\title{
STRATEGIES FOR TRANSLATING WESTERN LITERATURE INTO ARABIC BETWEEN DOMESTICATION AND FOREIGNIZATION
}

http://dx.doi.org/10.47832/2757-5403.4-3.23

Laida SAIM ${ }^{1}$

\begin{abstract}
:
Translation is the core of human civilization. It consists in transferring texts from their original language to another making it perfectly harmonious in a foreign intellectual and cultural context, using methods and procedures that insure a translation as correct as possible. Considering the value of literature in constructing civilizations, we can clearly see that translation is as important as literature itself and even more. This is due to the fact that this later has always been an important factor in the prosperity and development of nations. In fact, literature is considered as the holder for people's thoughts and culture, and a record of their history. Translating literary texts from a language to another is a difficult and challenging task not only because of their content, but also for the different styles, creative formats, and rhetoric used by the author. So, what are the difficulties that hinder the translator's work during the transfer of literary creativity? What kind of strategies should he choose to make a balance the forces attracting him while transferring foreign literature from Western languages to Arabic? Domestication or foreignization?

And from there, we try in this paper to highlight some of the problems facing the literary translator, especially by observing and analyzing two Arabic translations by Hafiz Ibrahim and Munir Al-Baalbaki of the international French novel Les Miserables, entitled "strategies for translating Western literature into Arabic between domestication and foreignazation.
\end{abstract}

Key words: Language, Literature, Translation Methods, Domestication And Foreignization, Translation Strategy.

\footnotetext{
${ }^{1}$ Dr. , Algiers 2 University, Algeria, laida.saim@univ-alger2.dz, https://orcid.org/0000-0003-3400-3747
}

Copyright $(\odot$ Published by IJHER Journal, www.ijherjournal.com

Rimar Academy, Fatih, Istanbul, 34093 Turkey

Published:

01/08/2021 
استراتيجيات ترجمة الأدب الغزبي إلى العربية بين التقريب والتغريب

لعايدة صايم2

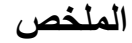

تقع الترجمة في صلب الحضارة الإنسانية، فهي عبارة عن نقل نص من لغناف لغته الأصلية إلى إلى

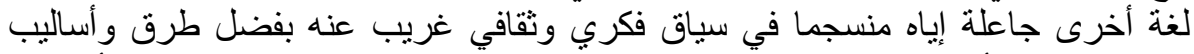

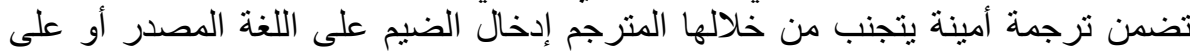

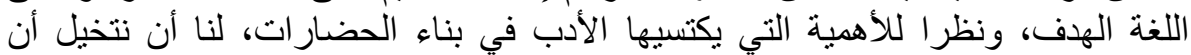

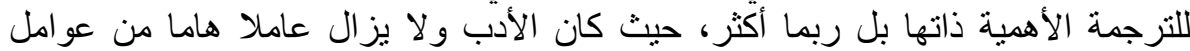

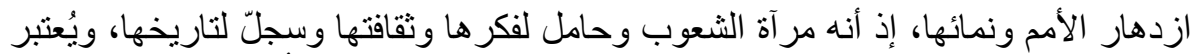

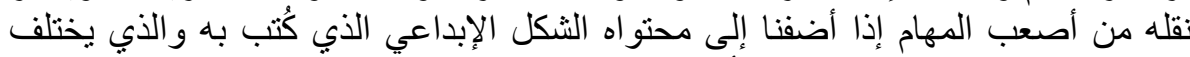

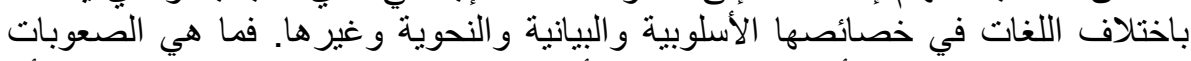

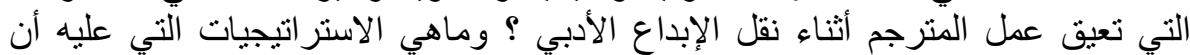

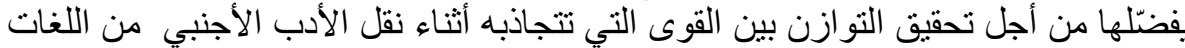

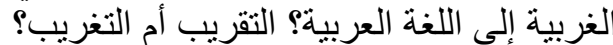

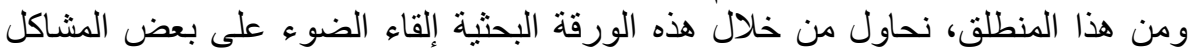

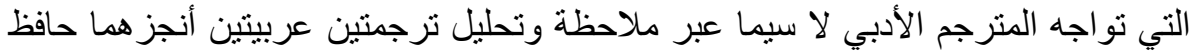

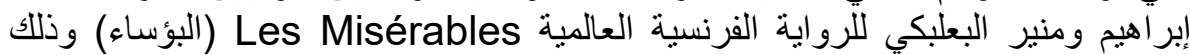

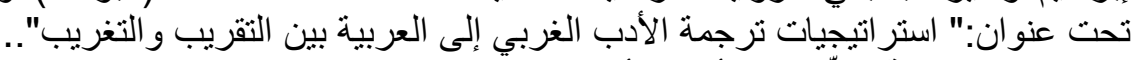

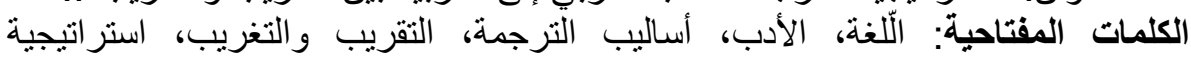
الترجمة.
\end{abstract}

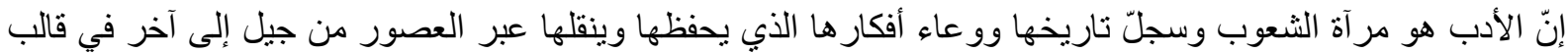

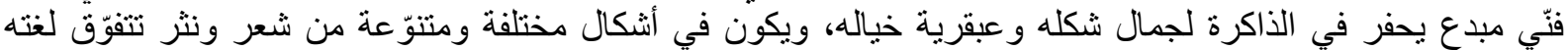

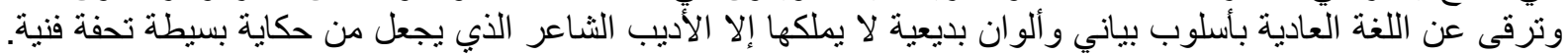

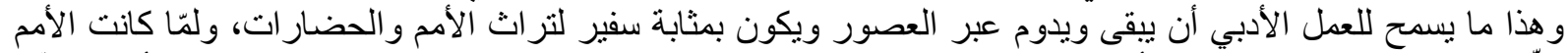

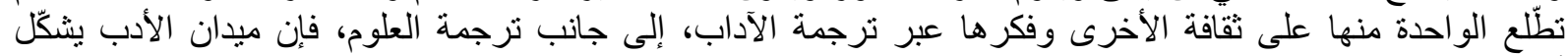

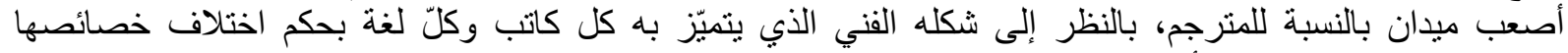

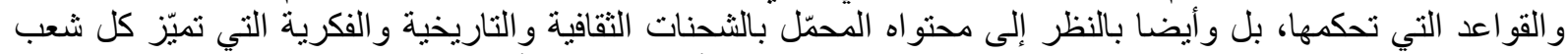

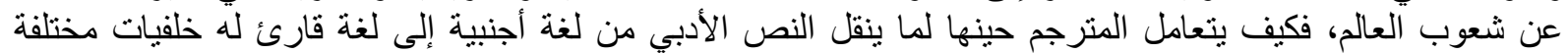

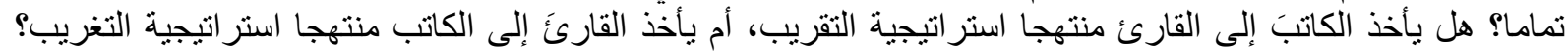

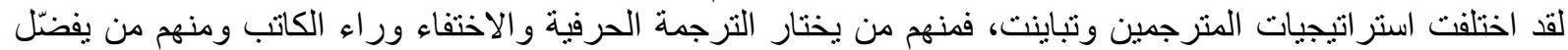

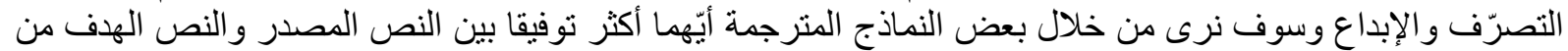

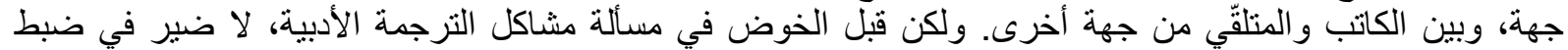

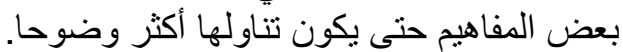

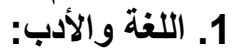

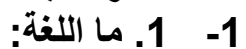

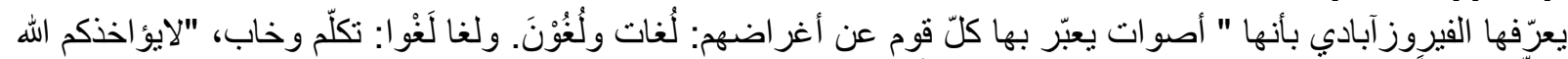

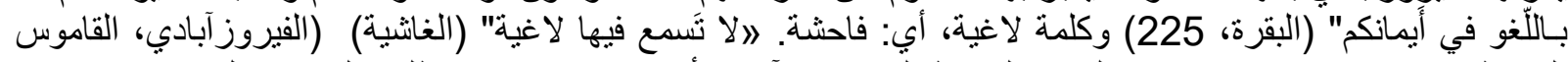

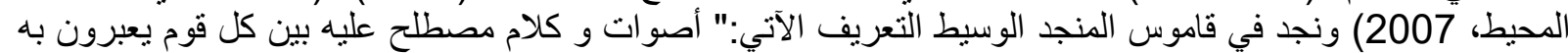

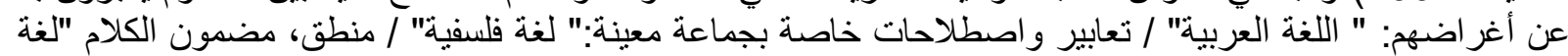


العقل" /" لغة الصم و البكم" هي لغة أو فن التخاطب بالإشارات الإصبعية، شائعة الاستعمال عند الصم و البكم (المنجد

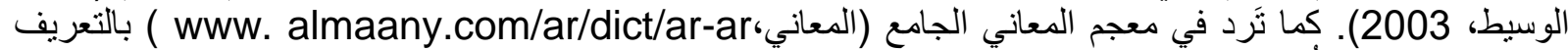

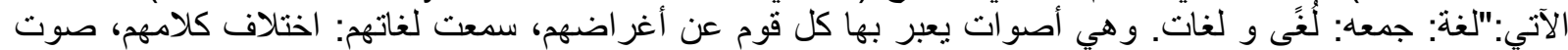

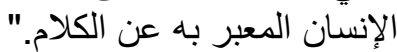

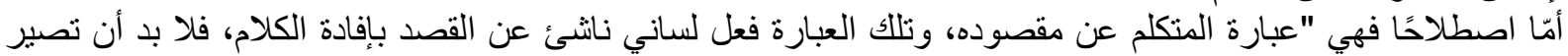

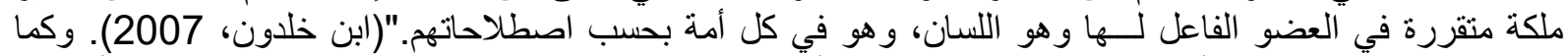

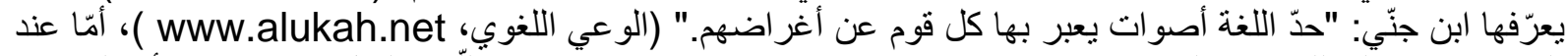

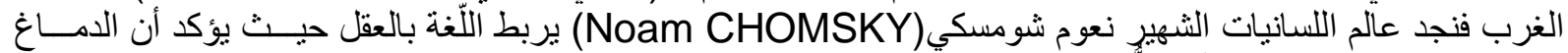

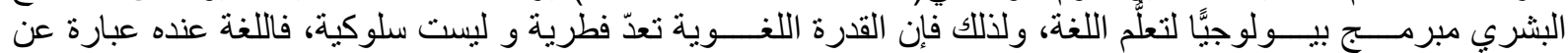

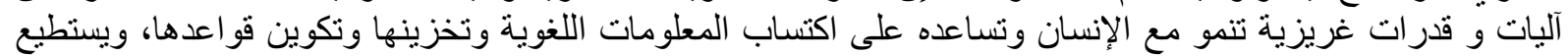

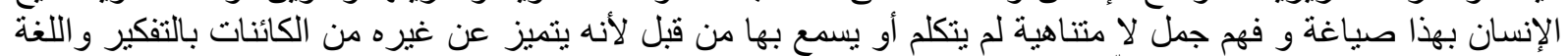

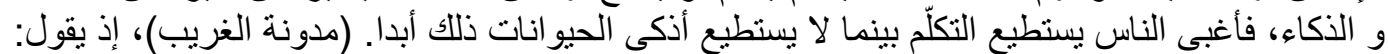
« Nous parlons comme nous voyons, nous n'apprenons pas notre langue, elle est innée, inscrite dans notre biologie » (Culture-Langage)

" نحن نتكلم بنفس الطريقة التي نبصر بها، فنحن لا نتعلم لغتنا بل هي موجودة فينا بالفطرة، مسجّلة في تكويننا

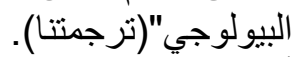

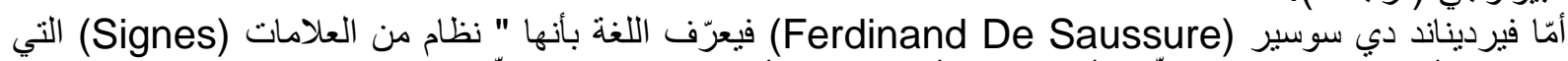

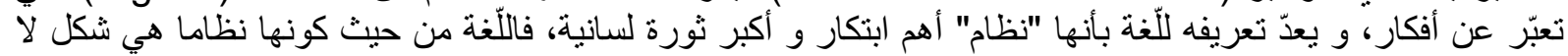

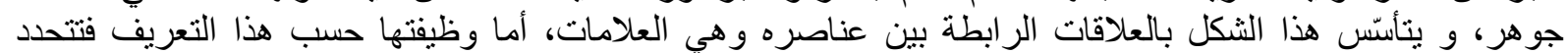

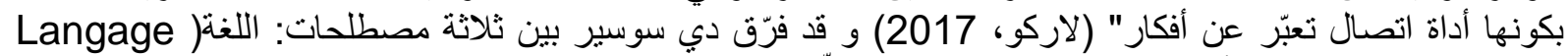

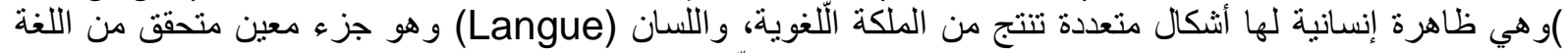

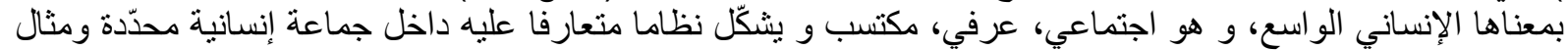

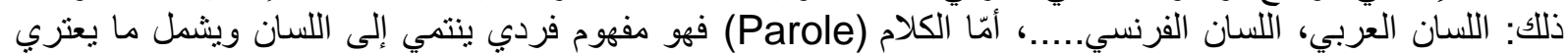

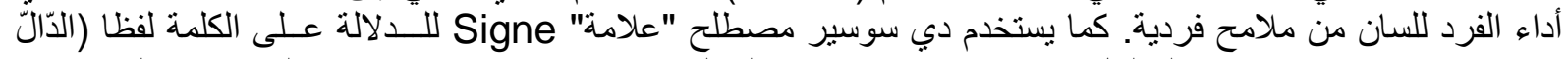

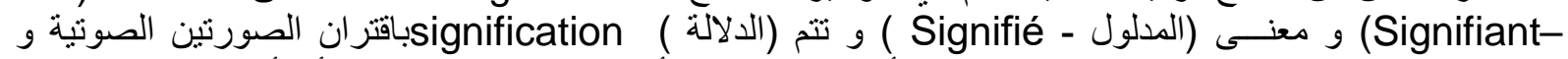

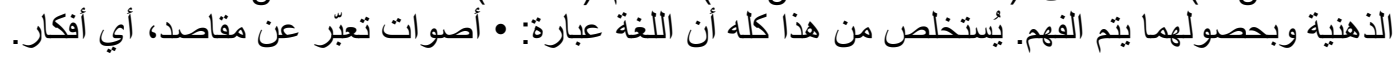

$$
\begin{aligned}
& \text { • أن هذه الأصوات تختلف من مجتمع إلى آخر. } \\
& \text { • • أنها تنظيم من الإشارات (الرمزية) المغايرة. } \\
& \text { • و أنها تنظيم ذهني مرتبط بعناصر لفظية. }
\end{aligned}
$$

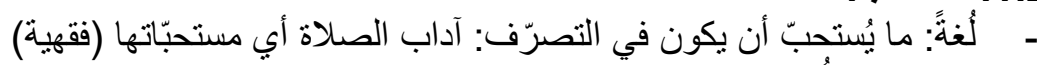

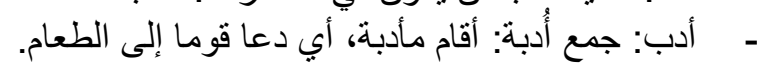

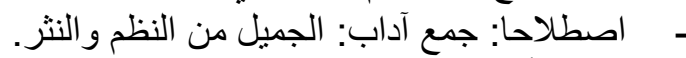

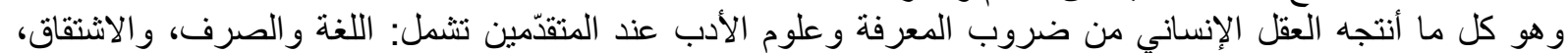

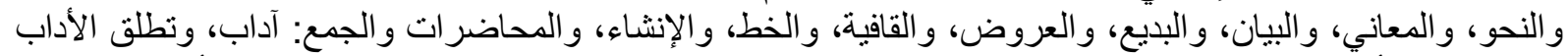

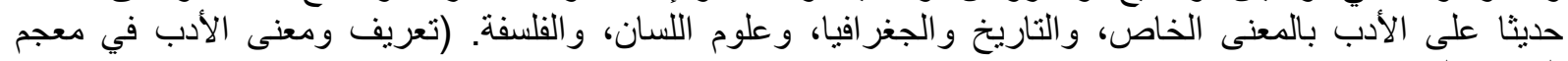

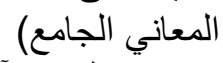

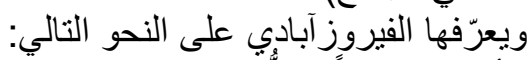

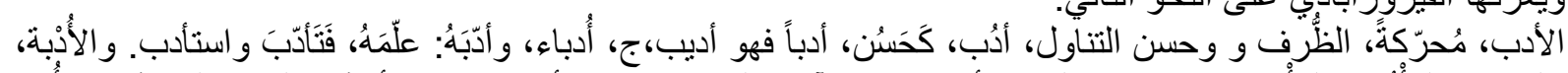

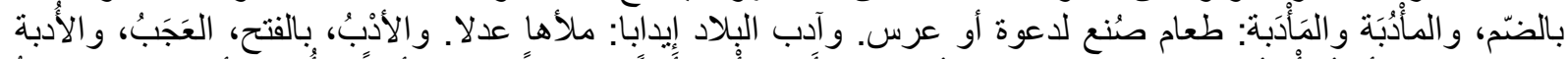

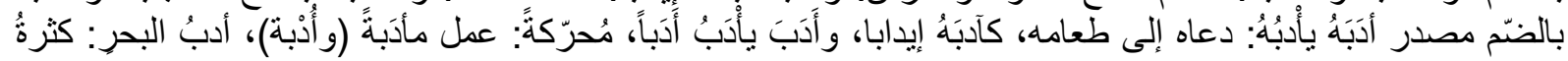

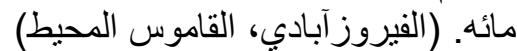

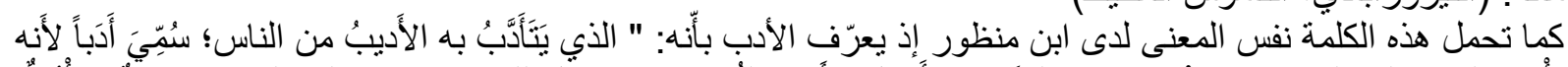

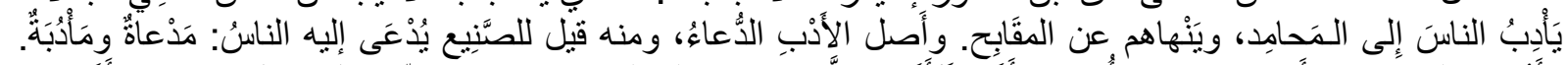

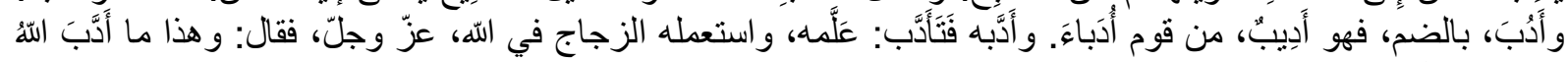

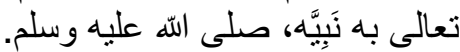

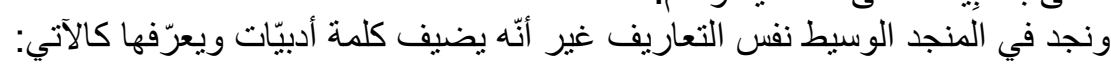




\section{STRATEGIES FOR TRANSLATING WESTERN LITERATURE INTO ARABIC}

BETWEEN DOMESTICATION AND FOREIGNIZATION

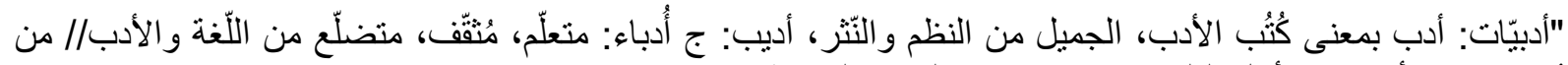

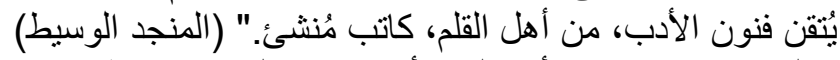

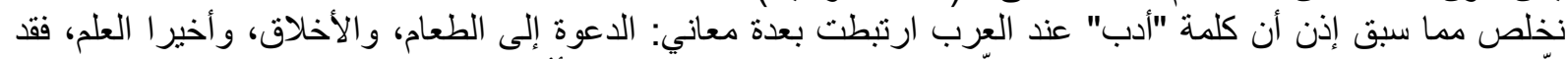

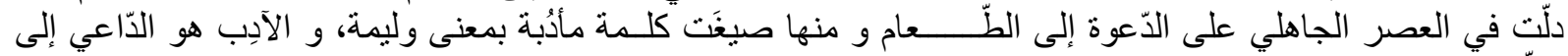

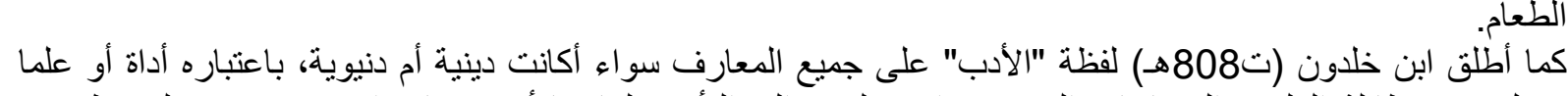

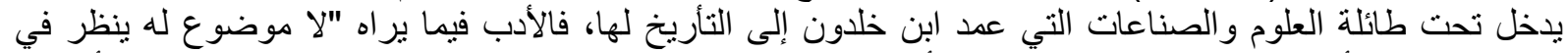

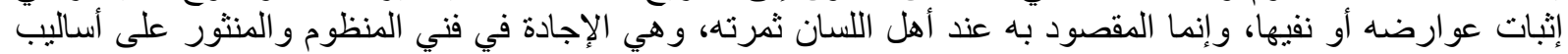

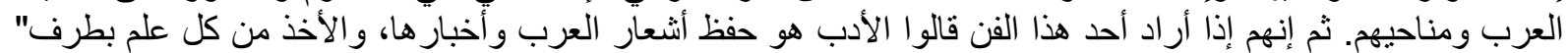

(ابن خلدون، 2007) و بُعيد الحملة الفرنسية على مصر، منذ بداية الاحتكالك العربي ـ الأوربي، أصبحت الكلمة ثُشتخدم في اللغة العربية

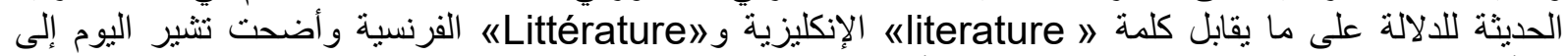

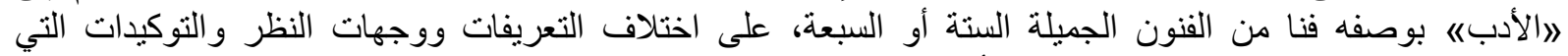

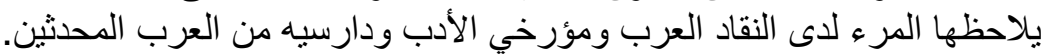

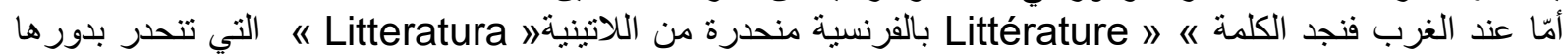

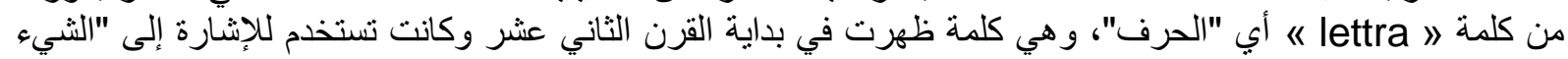

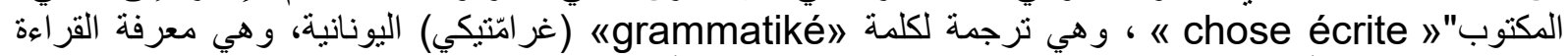

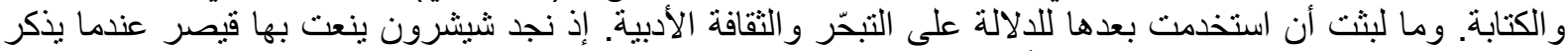

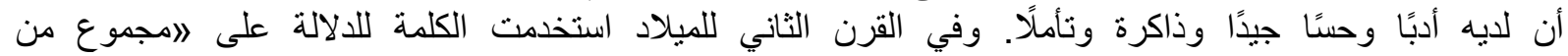

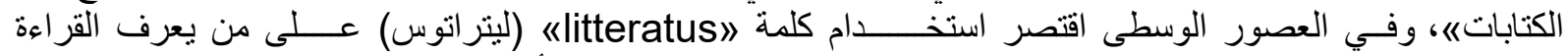

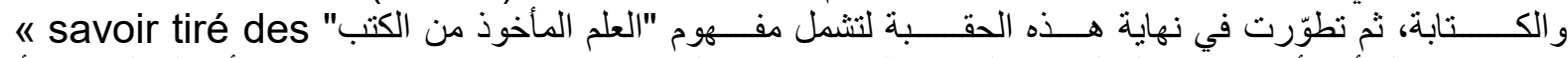

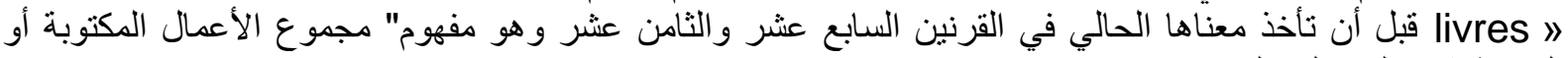

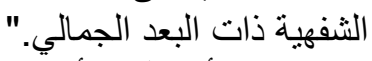

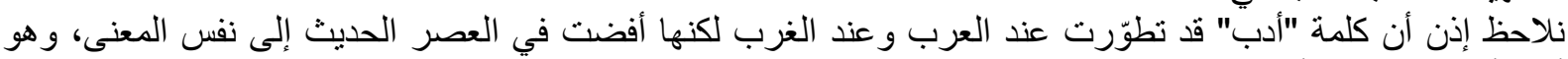

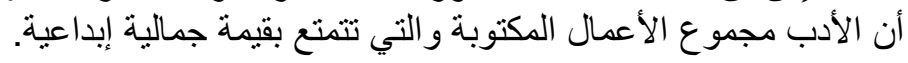

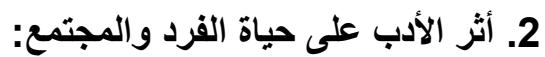

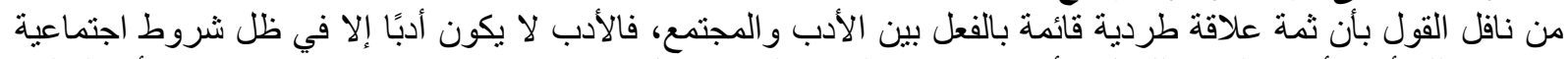

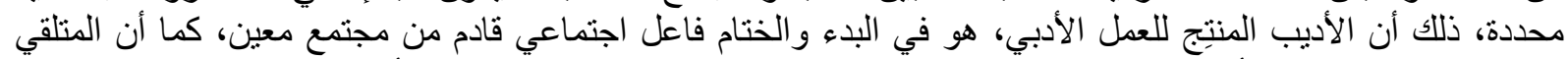

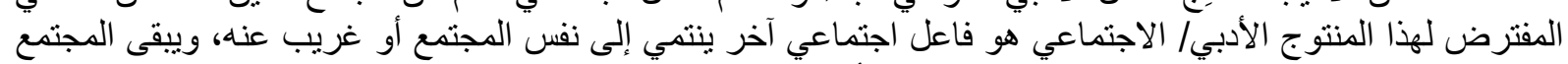

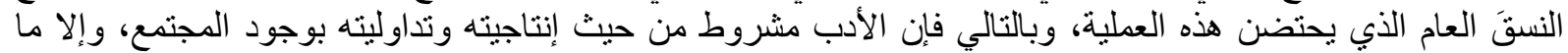

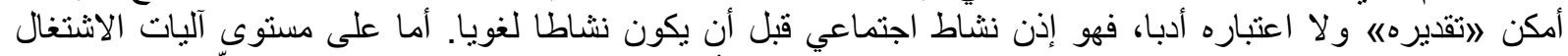

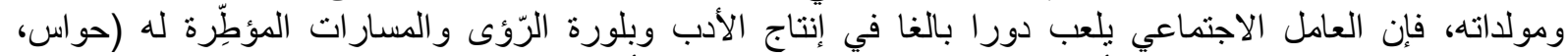

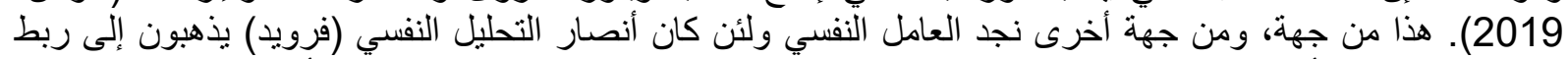

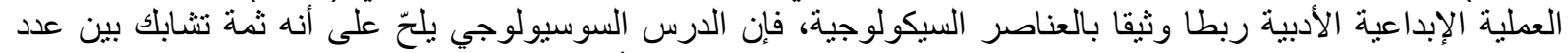

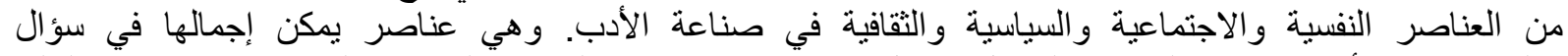

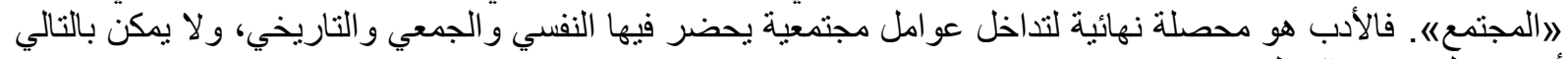

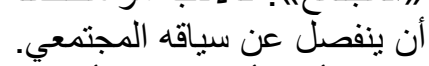

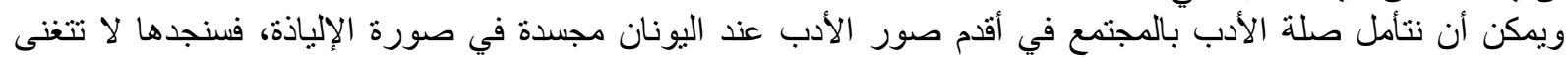

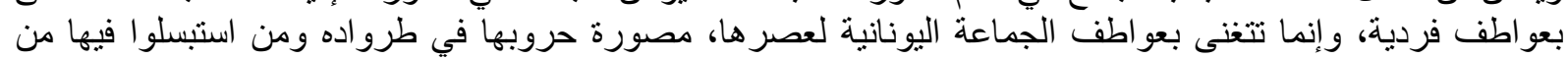

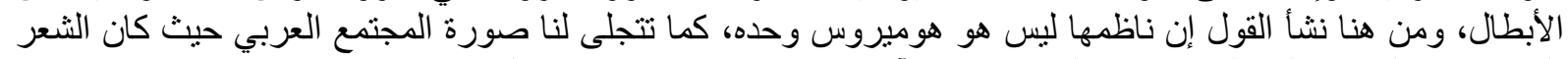

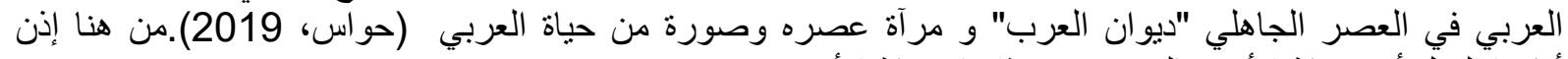

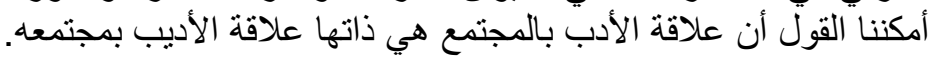

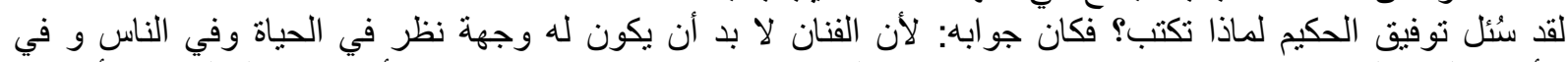

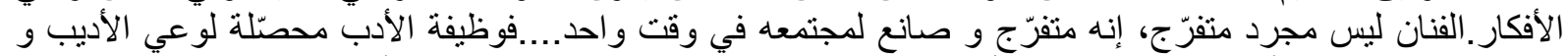

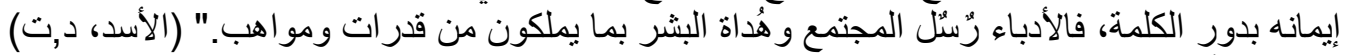

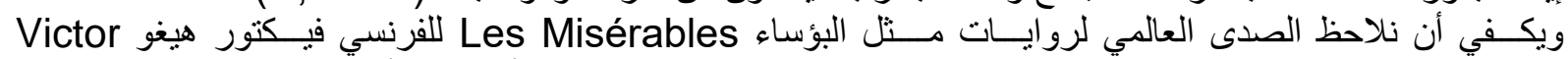

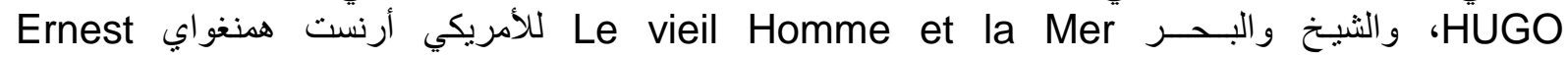


Fiodor Hemingway

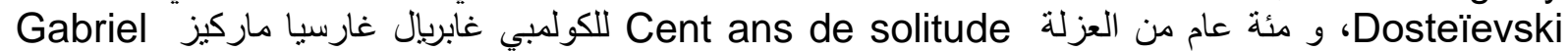
Garcia Marquez

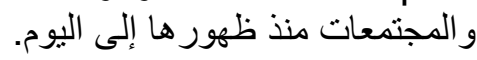

3. إنكالية ترجمة النص الأدبي في السياق اللغوي والثقافي والاجتماعي:

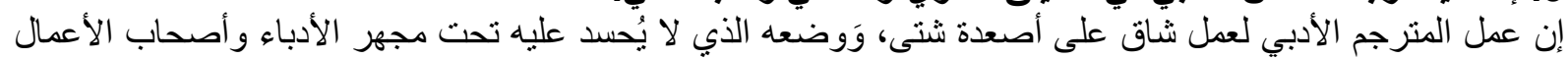

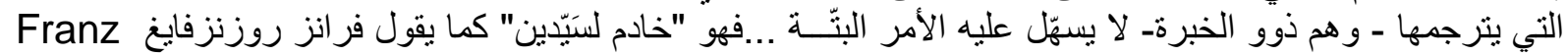
.Rosensweig لمّا ننظر إلى النص الأدبي ك"موضوع" للترجمة، فإننا حتما سنجده موضو عا معقدا ومتعدد السمات، من حيث النكل كما

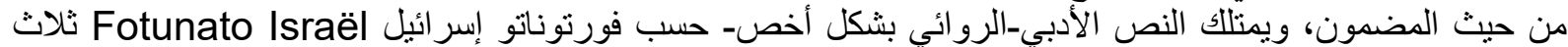

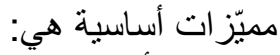

$$
\text { • • أنه موضهو موضوع لساني، أنهابي، }
$$

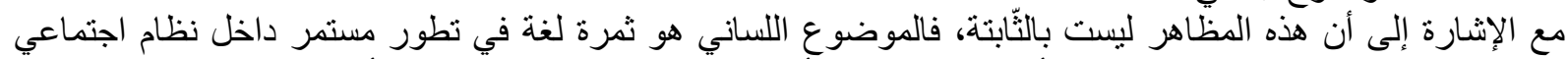

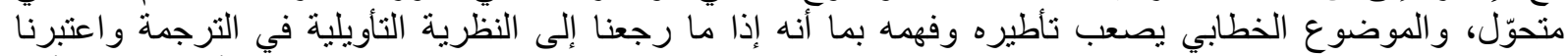

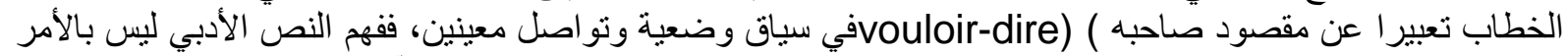

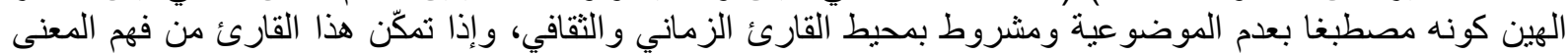

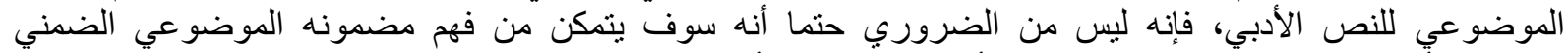

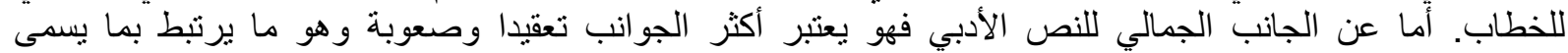

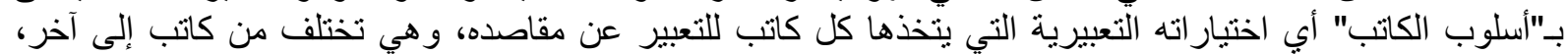

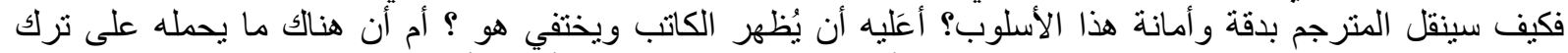

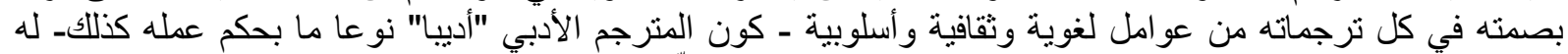

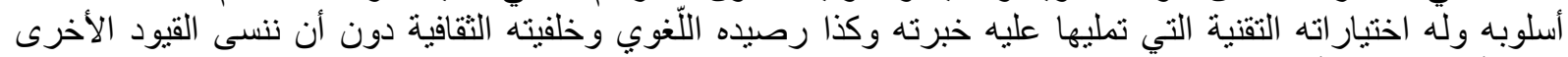

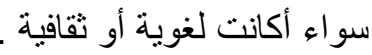

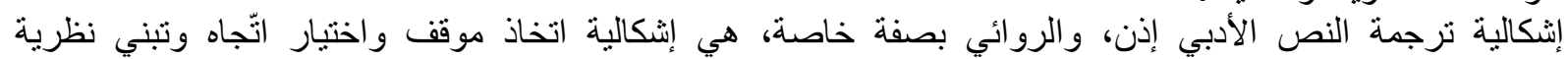

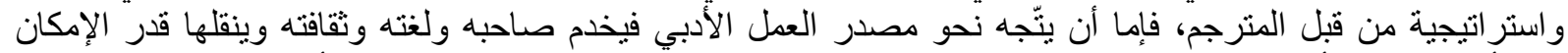

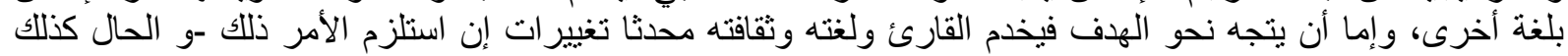

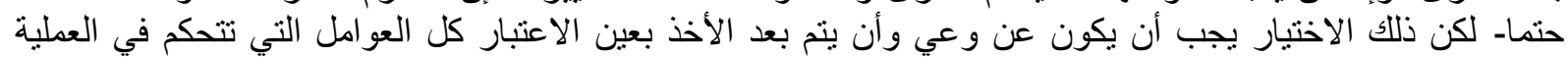
الترجمية وأهمها المتلقي.

\section{1.4. الترجمة الأدبية في مفترق طرق النظريات و الاستراتيجيات:}

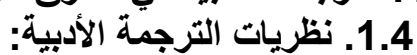
لقد اختلفت الأراء وتباينت حول الترجية الأبرة الترة الأدبية في أوساط المنظّرين لها بين دُعاة للنص المصدر (Sourciers) ودُعاة

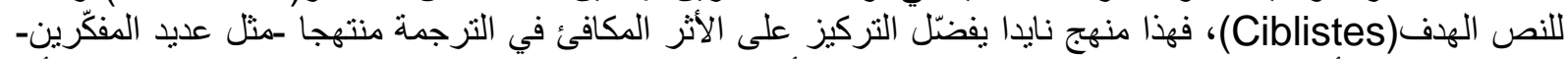

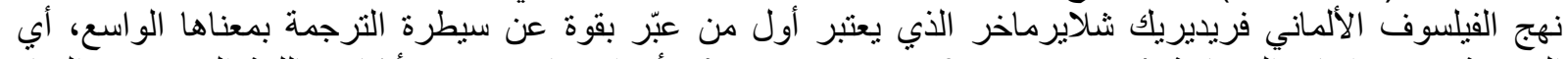

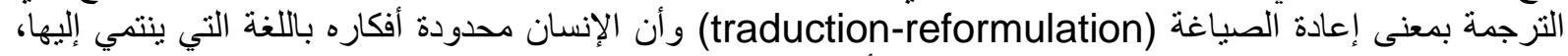

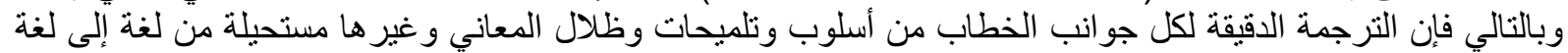

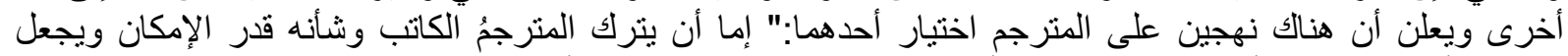

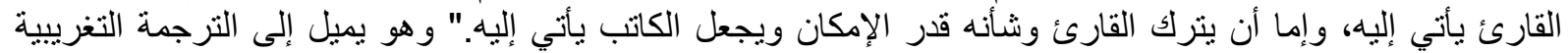
(traduction étrangéisante)

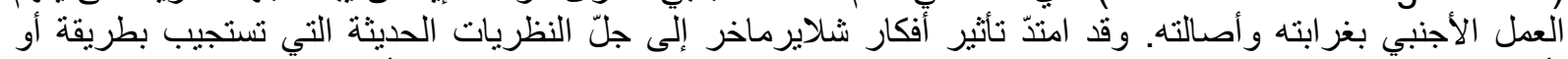

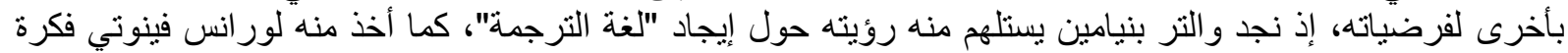

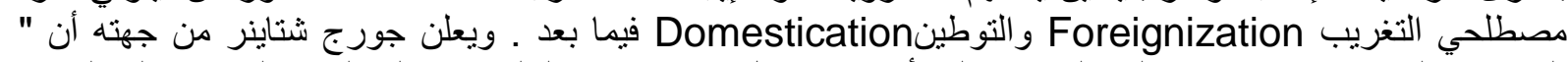

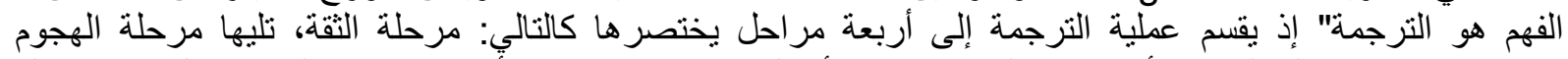

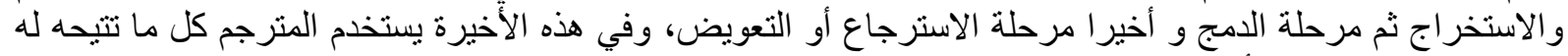

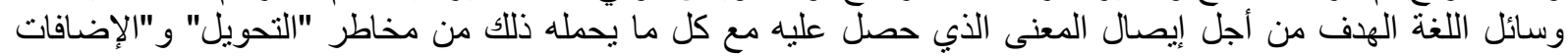




\section{STRATEGIES FOR TRANSLATING WESTERN LITERATURE INTO ARABIC}

BETWEEN DOMESTICATION AND FOREIGNIZATION

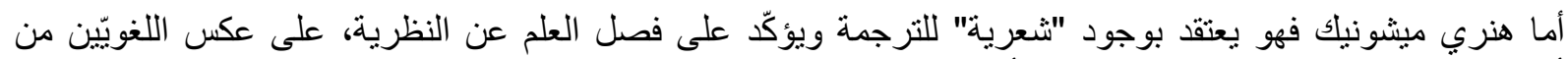

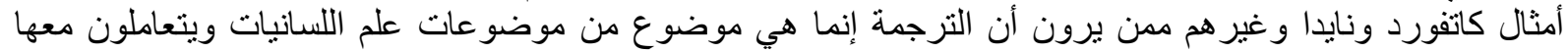

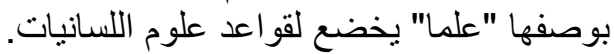

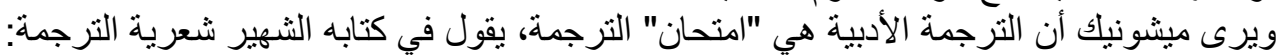
« La littérature est l'épreuve de la traduction. La traduction est un prolongement inévitable de la littérature." (Meschonic, 2012)

"الأبدب هو امتحان الترجمة. فالترجمة هي امتداد لا مناص منه للأدب."(ترجمتنا)

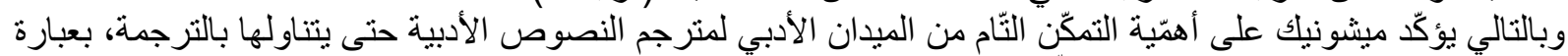

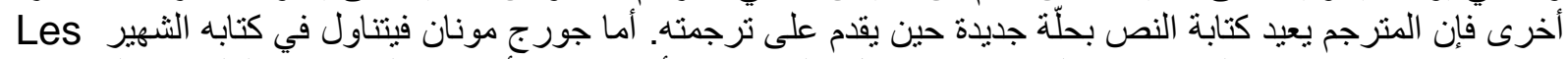
belles Infidèles

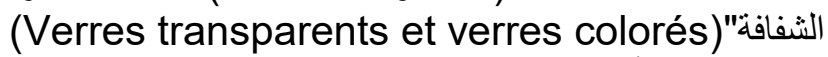

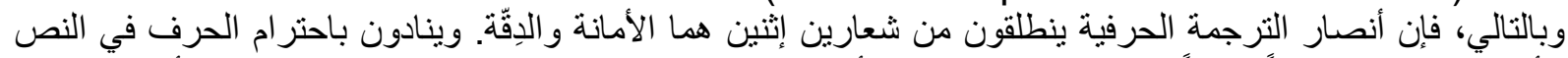

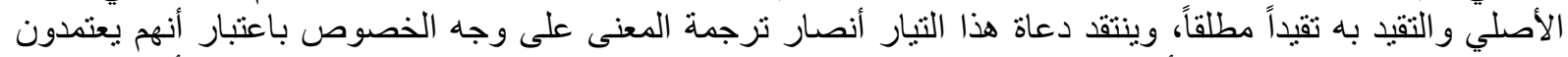

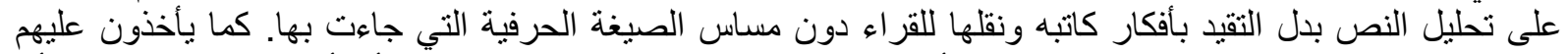

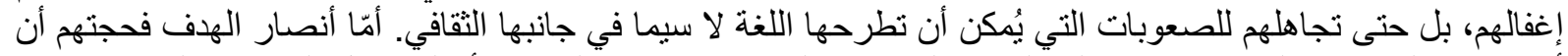

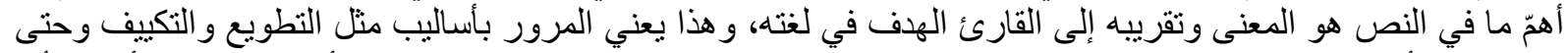

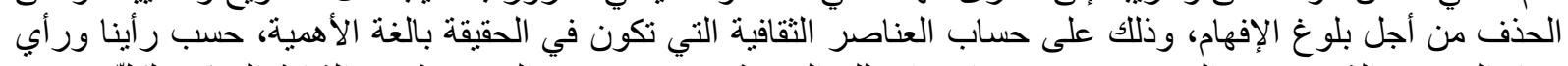

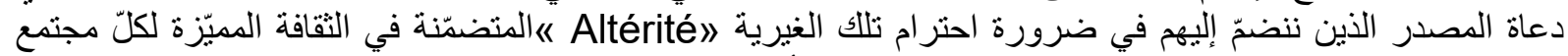

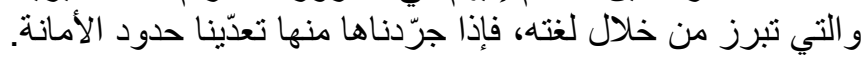
2.4. استراتيجيات الترجمة الأدبية:

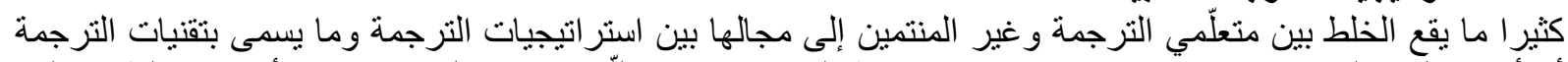

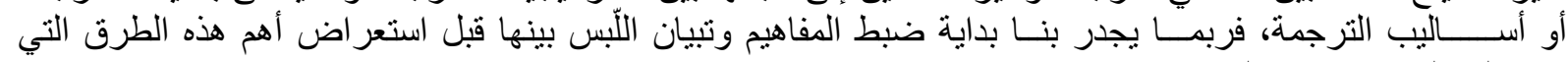
يستعملها المترجم في عمله.

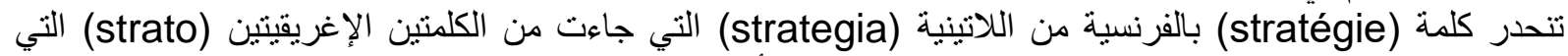

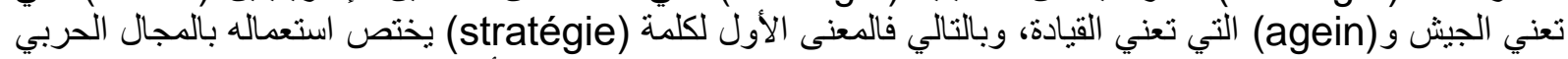

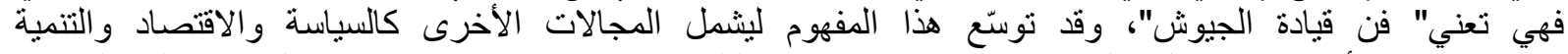

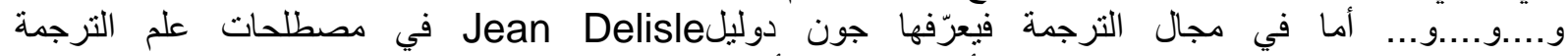

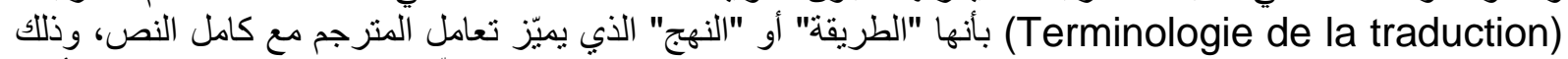

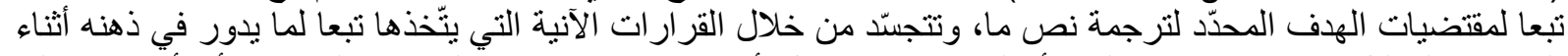

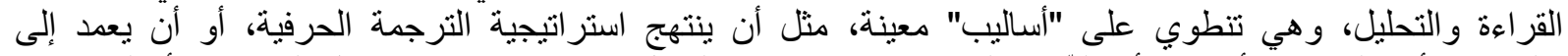

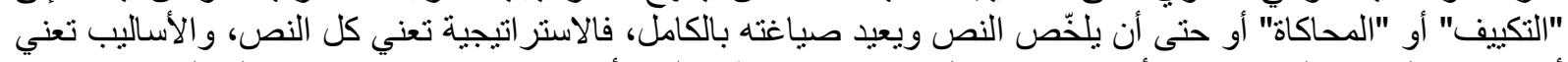

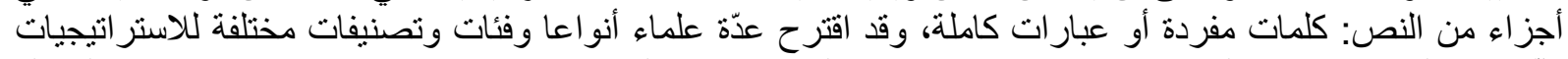

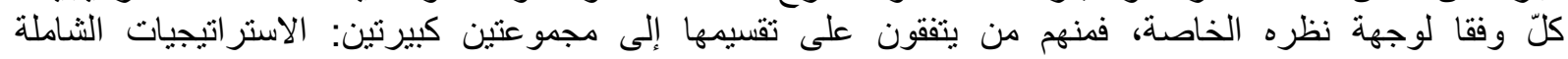
(Stratégies globales)

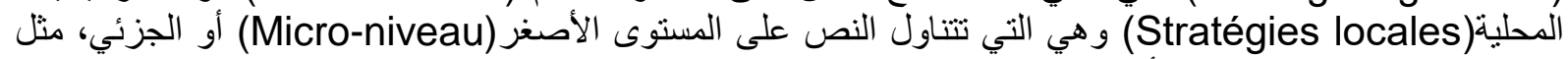

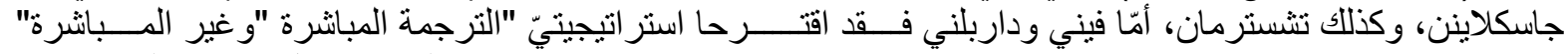
بينما وضع بيتر نيومارك من خلال نظريته السوسيو تئقافية (Stratégies de traduction directe et indirecte)

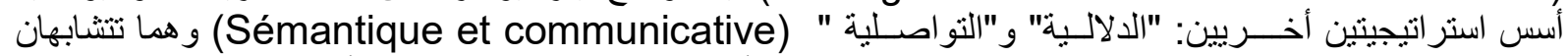

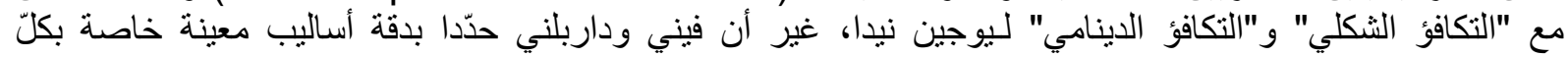
استر اتيجية.

$$
\text { 3.4. فينوتي و منهجي التغريب والتقريب: }
$$

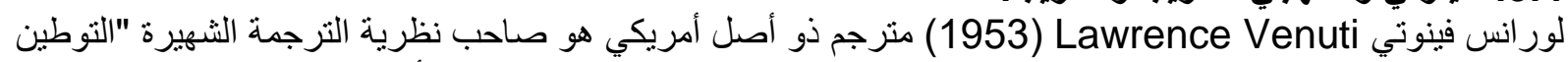
والتغريب" Domestication and Forignization التي تناولهاً في كتابه الأشهر invisibility:A History of Translation

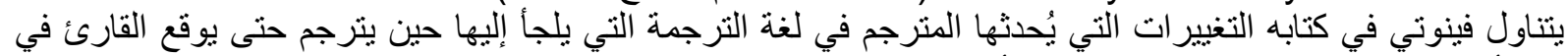

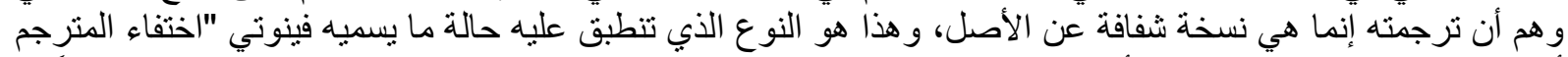

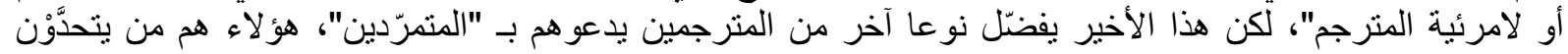


قدراتهم ويعتمدون على التجريب، فيخرجون بنص "غريب" في ثقافة اللغة الهدف وهذا ما يطلق عليه تسمية "الأمانة

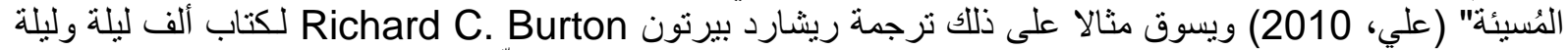

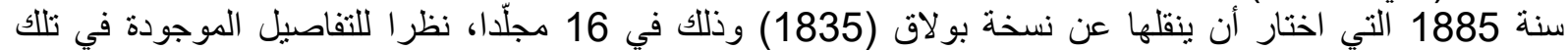

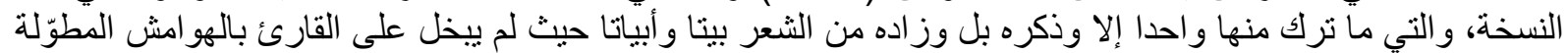

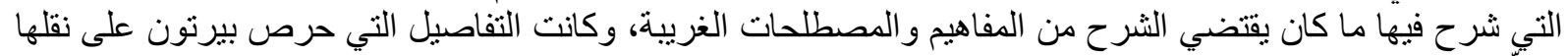

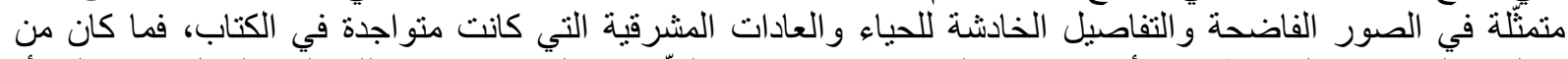

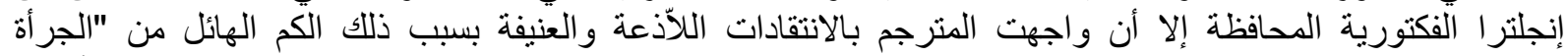

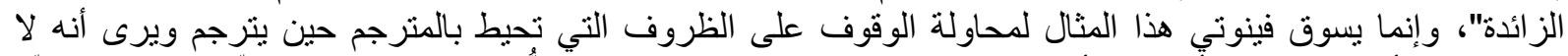

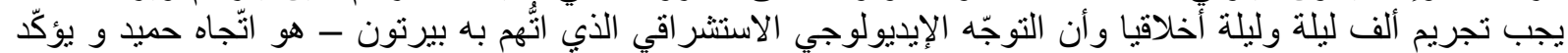

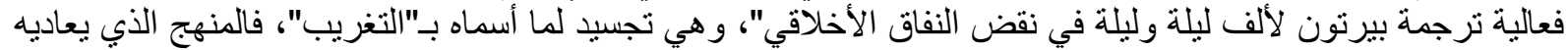

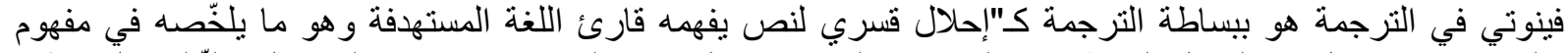

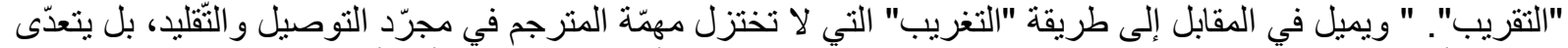

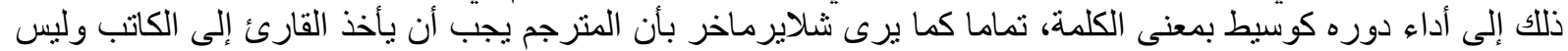

\section{5. تلقي الأدب الغربي لاى القارئ العربي:}

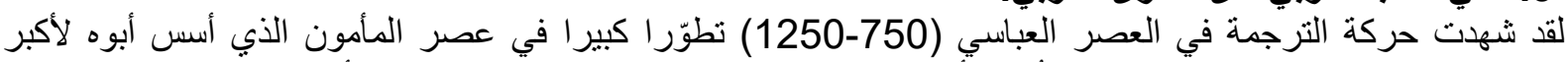

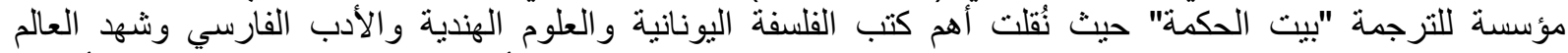

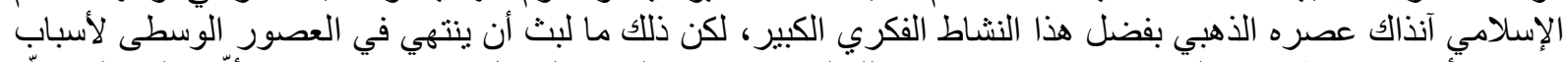

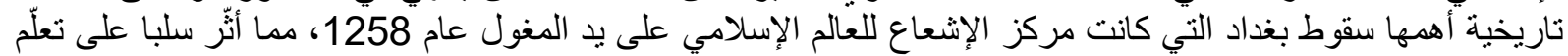

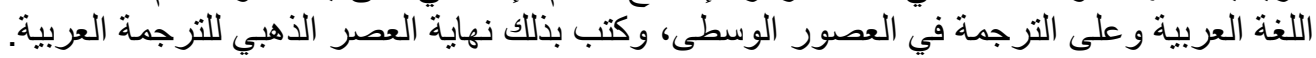

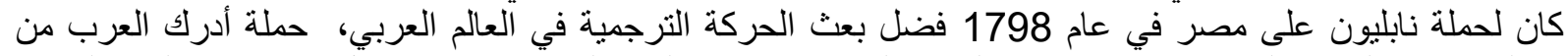

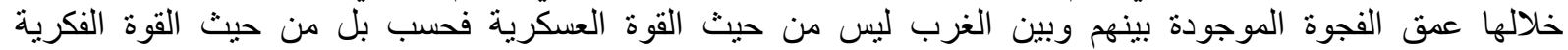

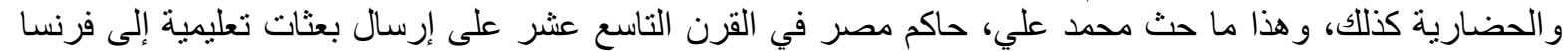

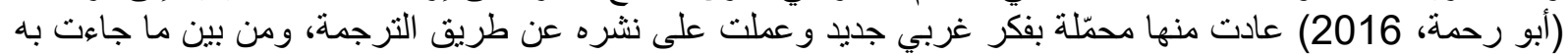

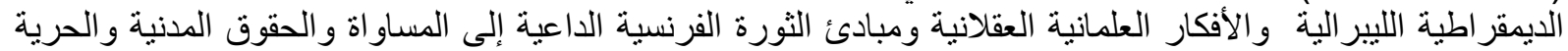

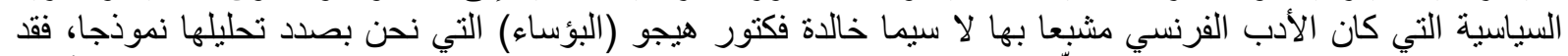

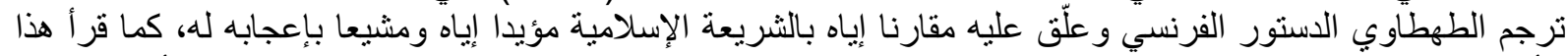

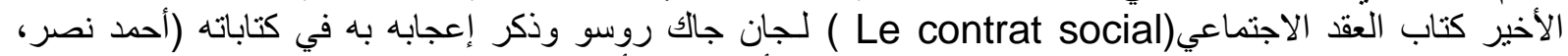

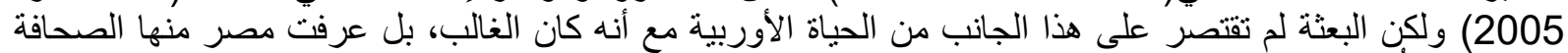

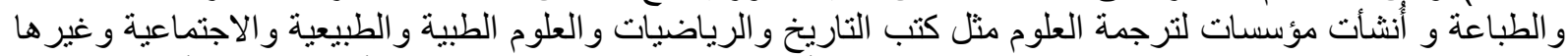

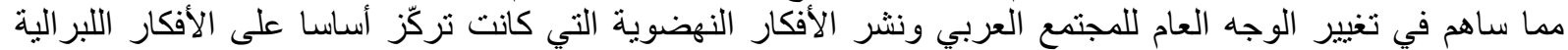

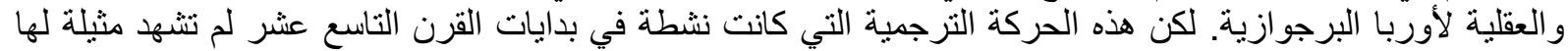

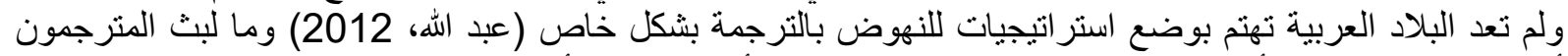

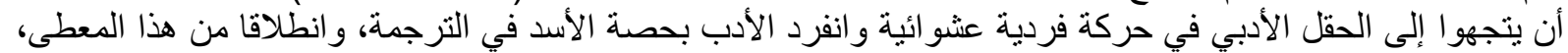

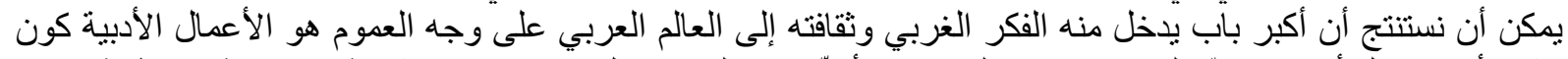

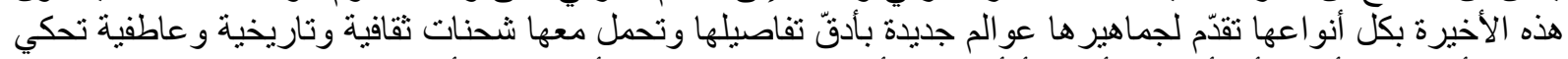

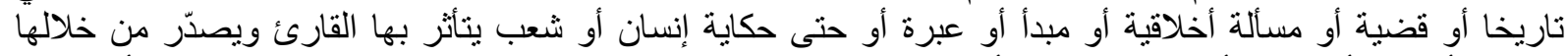

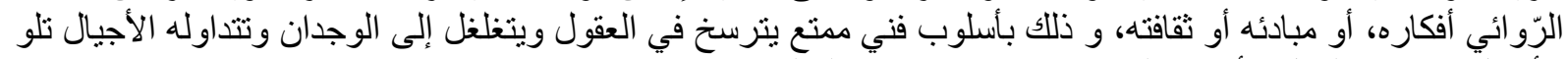

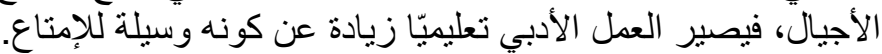

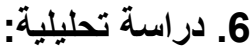
1.6 - مراءة في الرواية: الكاتب:

فكتور ماري هيجو Victor Marie HUGO (إكبو (1802-1802) أديب وشاعر وروائي فرنسي، ومن أبرز أدباء فرنسا

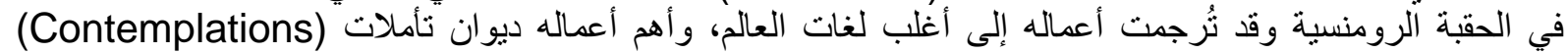

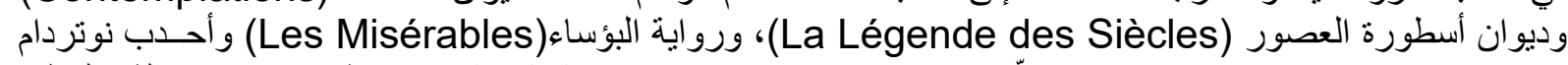
ودe bossu de Notredame)

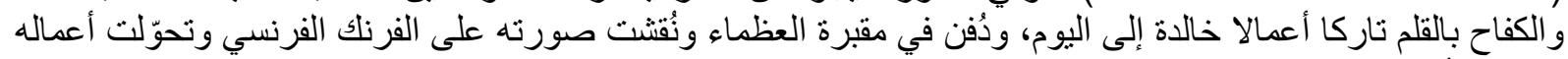

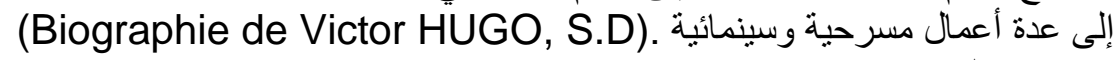

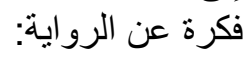


البؤساء هي رواية فلسفية دينية تعبّر عن نهوض الإنسان من سقطاته و عثراته بالندم و التوبة بعد صر اع اع مع نفسه، وبطل

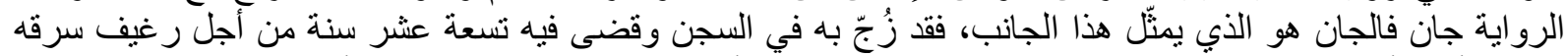

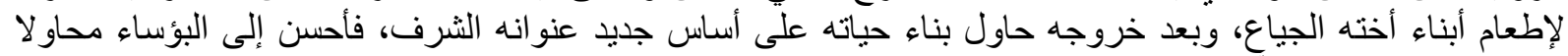

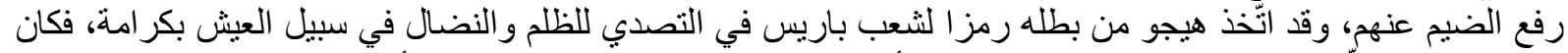

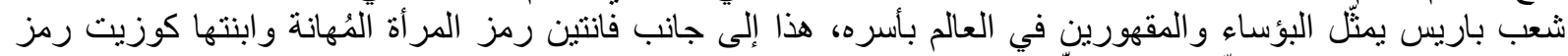
الطفولة المغتالة وكذا المحقّق جافير ممثّل الانصياع المطلق للسلطة.

2.6

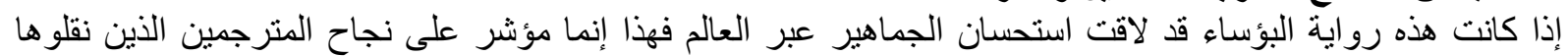

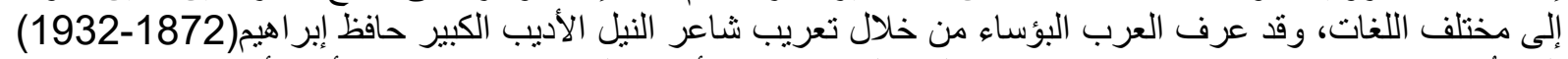

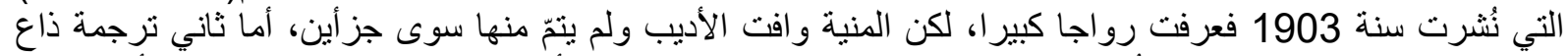

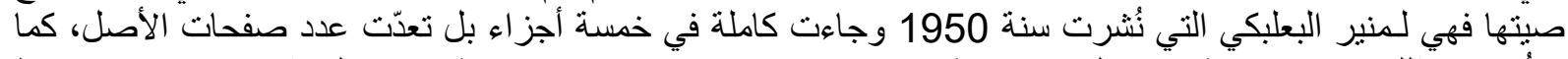

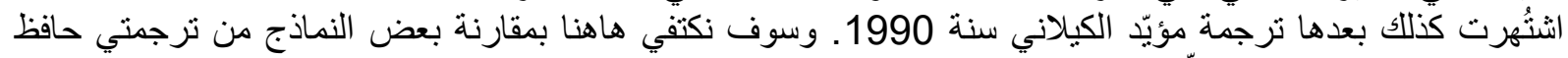

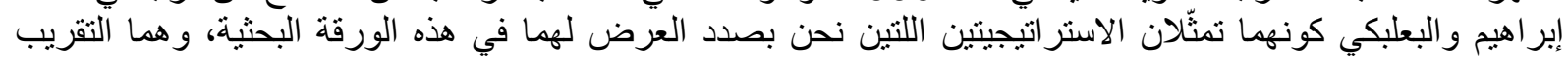
و التغريب.

النموذج الأول: (الترجمة الصرفية مقابل إعادة الصياغة)

«- Je ne puis vous donner à dîner.

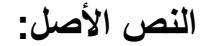

Cette déclaration, faite d'un ton mesuré, mais ferme, parut grave à l'étranger. II se leva.

- Ah bah ! mais je meurs de faim, moi. J'ai marché dès le soleil levé. J'ai fait douze lieues. Je paye. Je veux manger.

- Je n'ai rien, dit l'hôte.

L'homme éclata de rire et se tourna vers la cheminée et les fourneaux.

- Rien ! et tout cela?

- Tout cela m'est retenu.

- Par qui ?

- Par ces messieurs les rouliers.

- Combien sont-ils?

- Douze.

- Il y a là à manger pour vingt.

- Ils ont tout retenu et tout payé d'avance.

L'homme se rassit et dit sans hausser la voix:

- Je suis à l'auberge, j'ai faim, et je reste. » (Les Misérables) p.161, T1.

$$
\begin{aligned}
& \text { ترجمة منير البعلبكي: }
\end{aligned}
$$

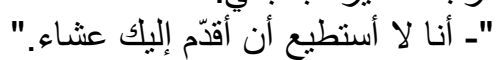

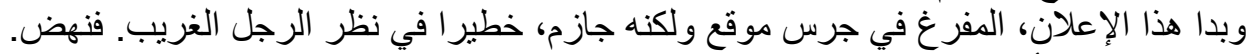

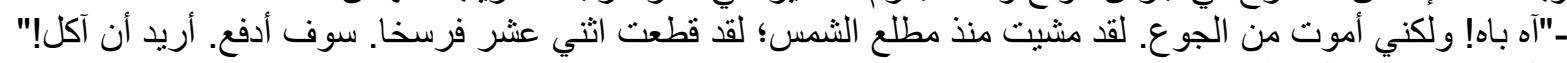

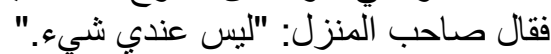

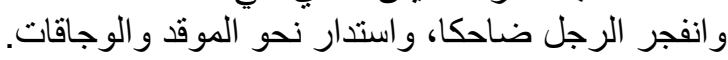

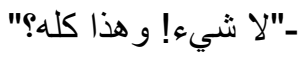

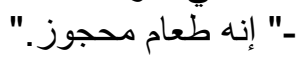

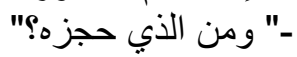
ـ - " هؤ لاء الَّادة سائقو العربات."

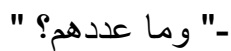

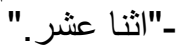

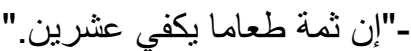


-" - لقد حجزوا الطعام ودفعو ا ثمنه كله مقدّما."

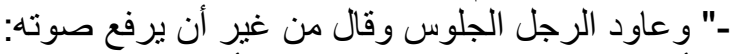

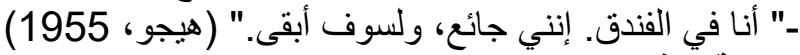

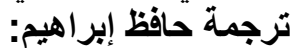

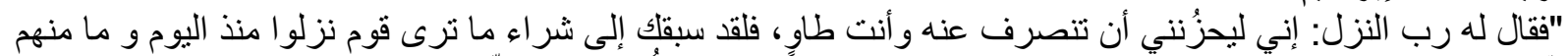

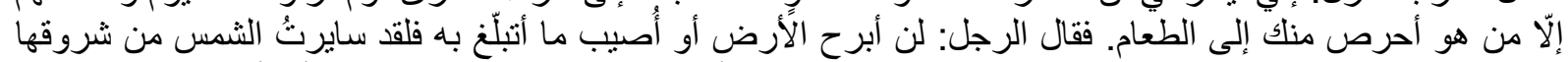

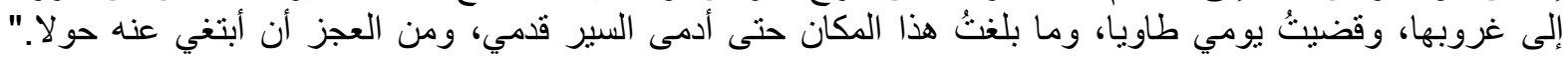

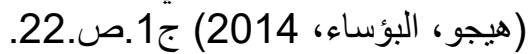
إن الملاحظ للنص الأصل واهل والترجمتين ليلاحظ بسهولة ومن الوهلة الأولى الفرق الثاسع بين الترجمة الأولى للنص

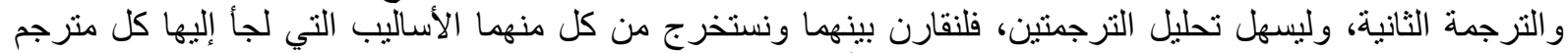

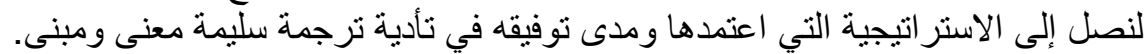

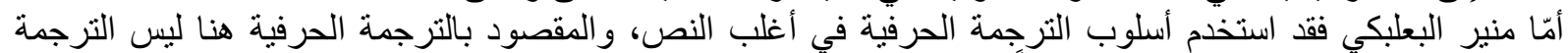

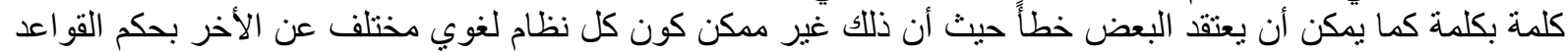

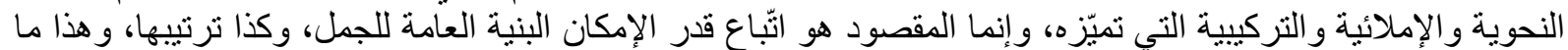

نلحظه في نرجمة الجملة الآتية مثّلا:

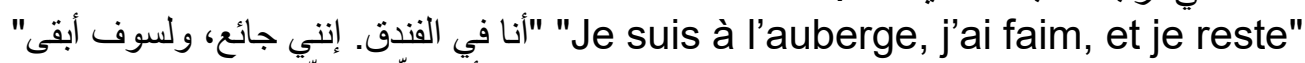

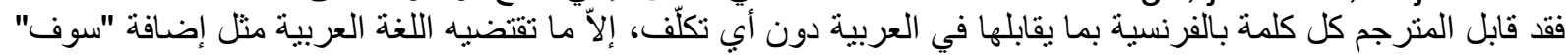

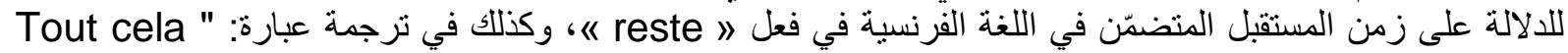
"m'est retenu

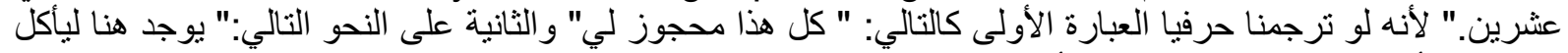

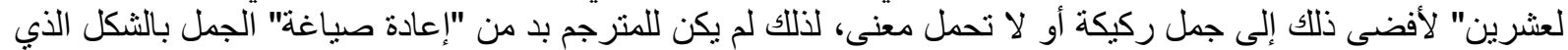

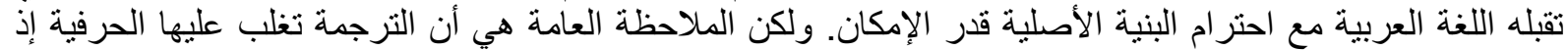

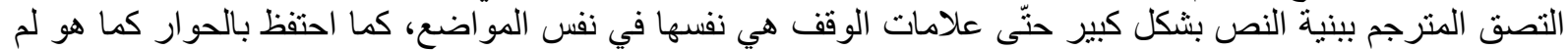

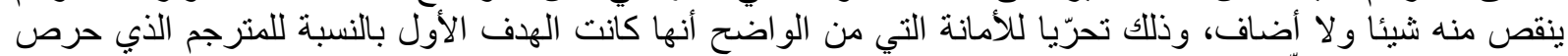

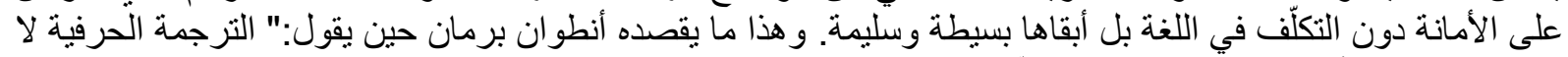

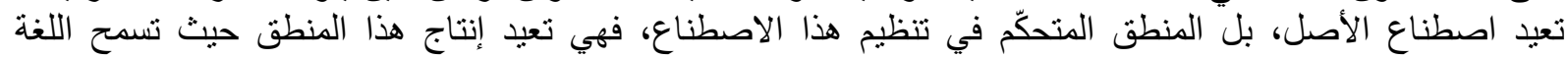

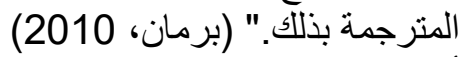

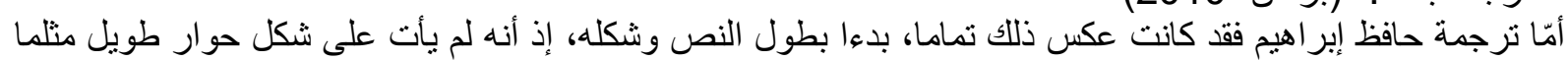

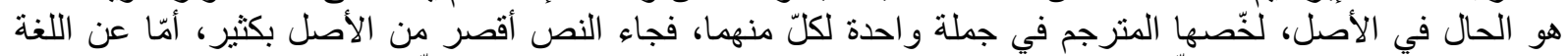

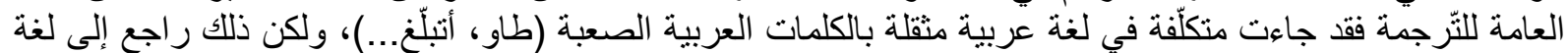

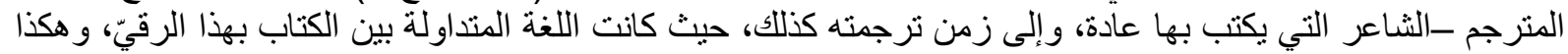

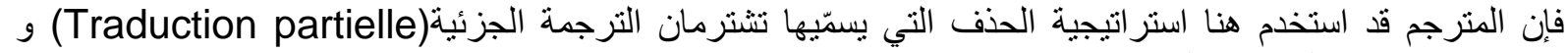

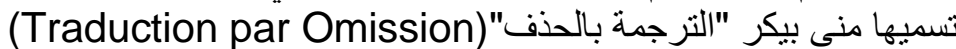

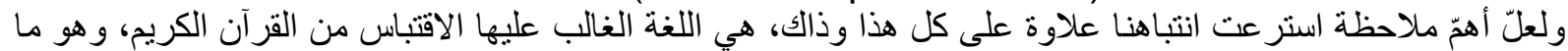

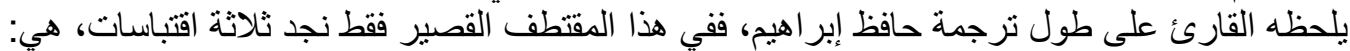

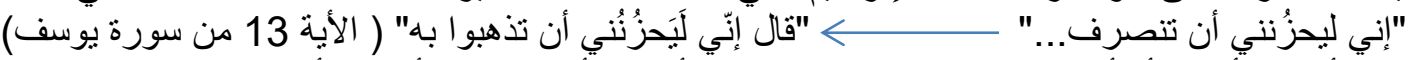

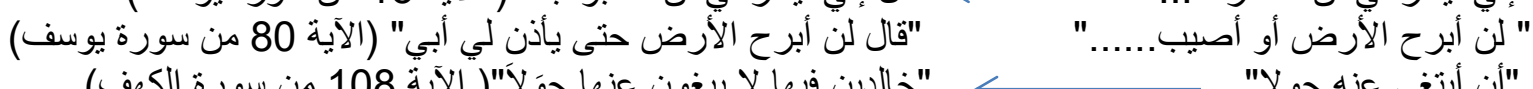

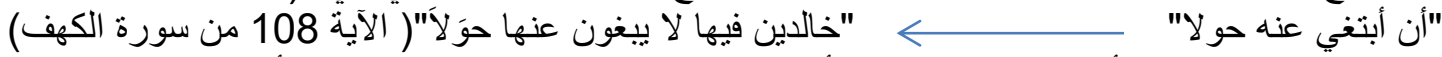

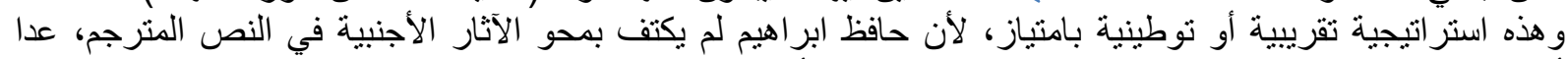

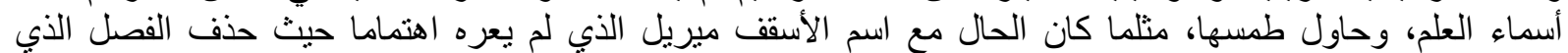

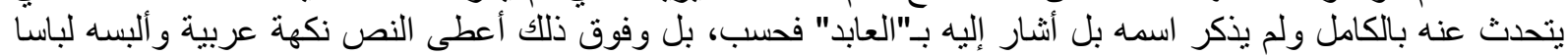

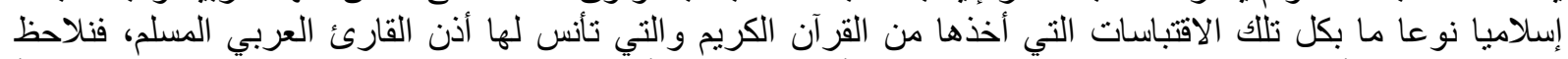

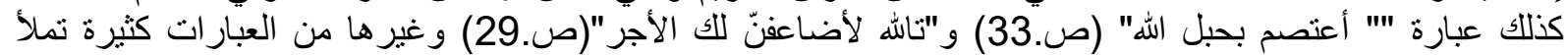
النص المترجم من بدايته إلى نهايته.

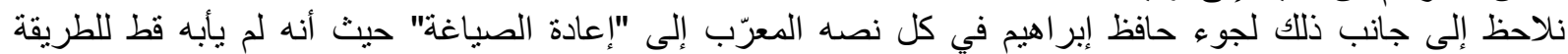

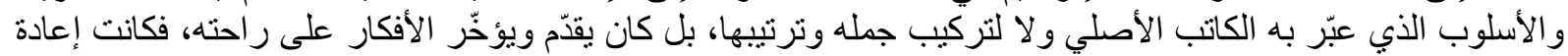

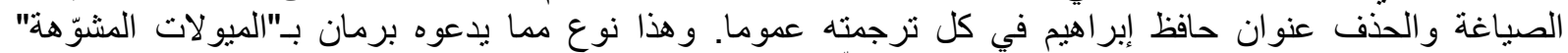

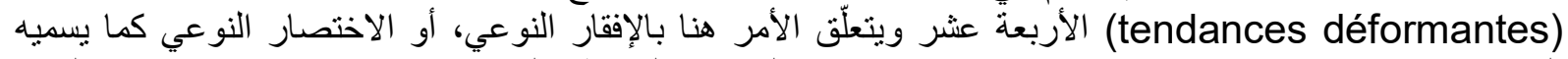

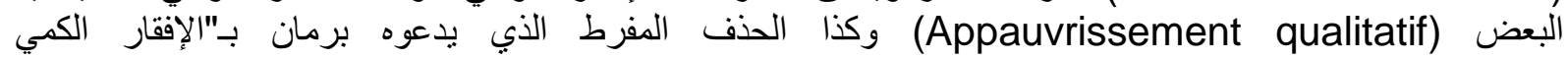


ويعتبر هذا مساسا بالنسيج المعمي للعمل وبنمط معجميته (Appauvrissement quantitatif)"

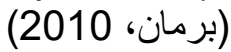
النموذج الثاني:( الاقتراض مقابل الحذف)

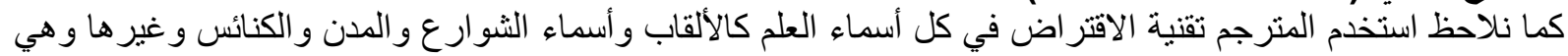

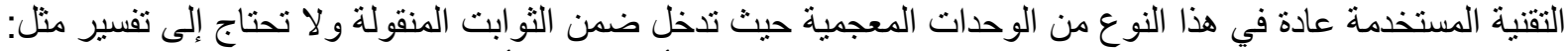

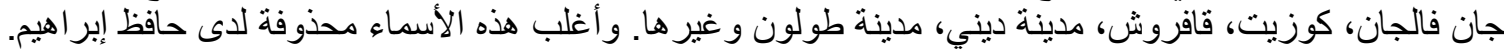

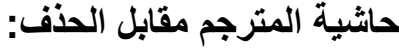

وعودة إلى أساليب منير البعلبكي، فإننا نجد الأخير يكثر مما يسمى بـ"حاثية المنرجم" (La note du traducteur)

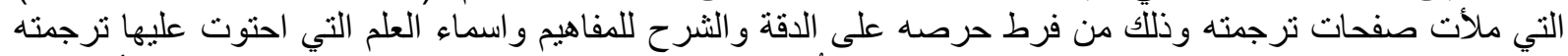

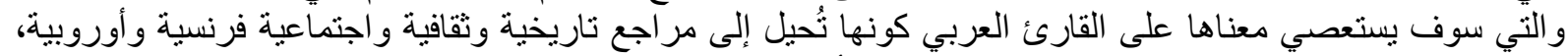

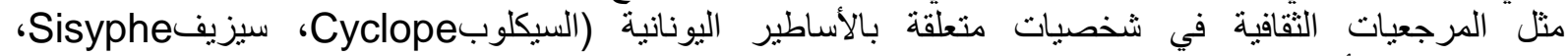

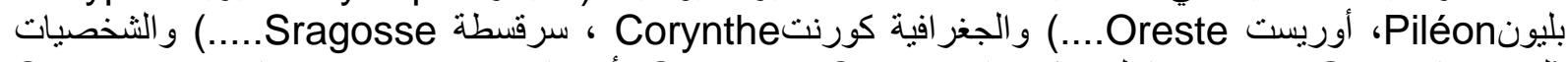

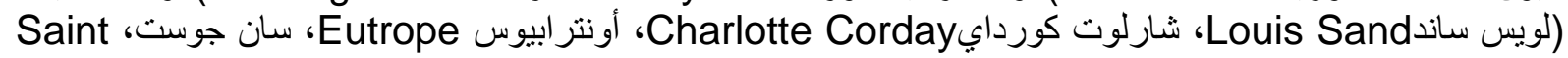

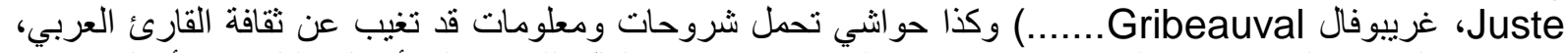

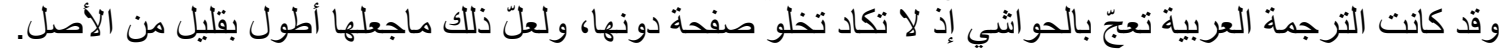

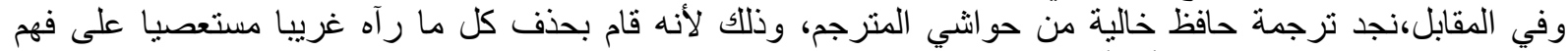

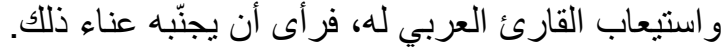

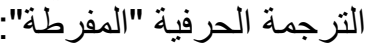

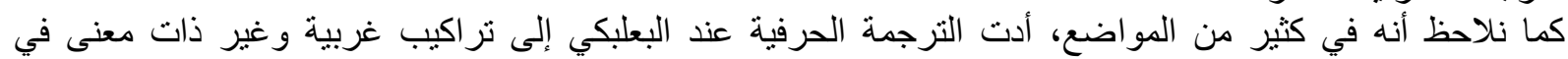

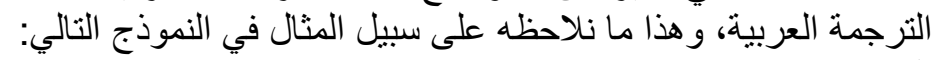

النموذج:

« Cela doit être du vrai vin. Il est heureux que Grantaire dorme, observa Bossuet. S'il était debout on aurait de la peine à sauver ces bouteilles-là. » p.19.T.5

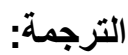
"ولاحظ بوسوويه: ينبغي أن تكون خمر ا أصلية. من حسن الحظ أن غر انتير نائُ: ولو قد كان قائما على رجليه إذن لكان

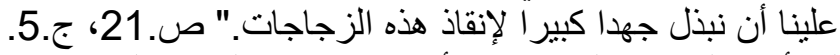

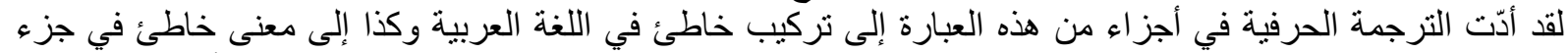

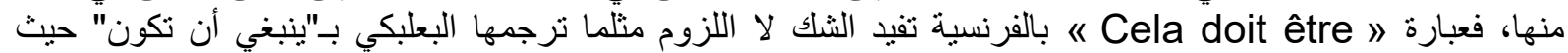

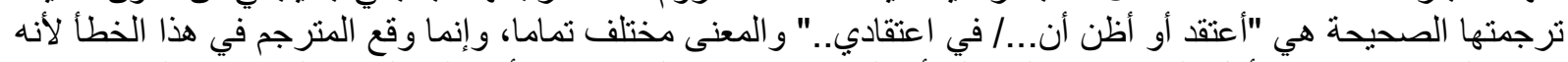

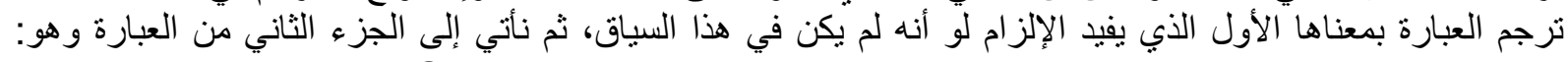
"S'il était debout on aurait de la peine à sauver ces bouteilles. "

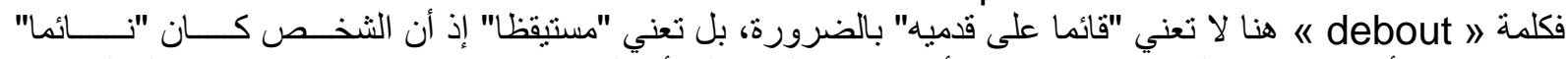

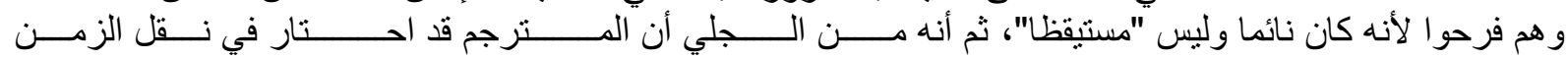

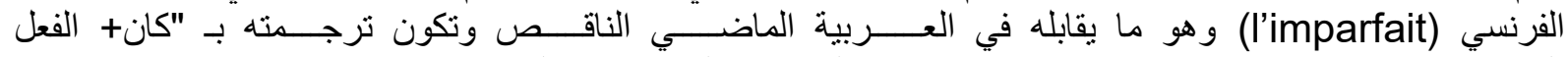

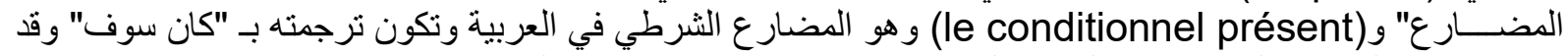

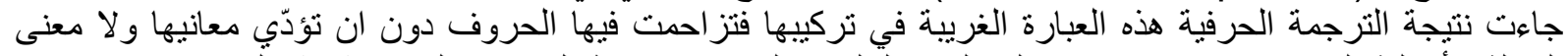

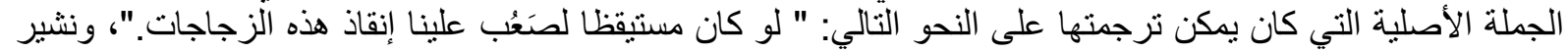

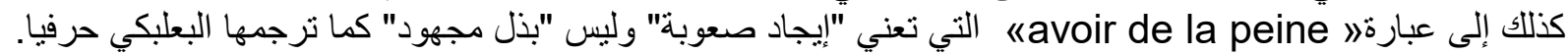

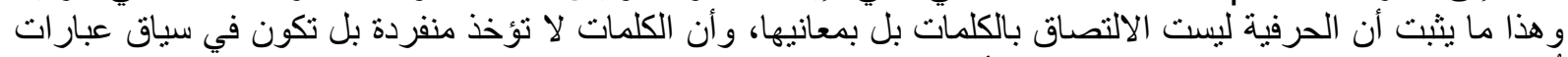

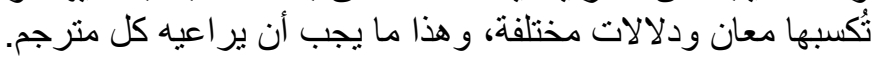

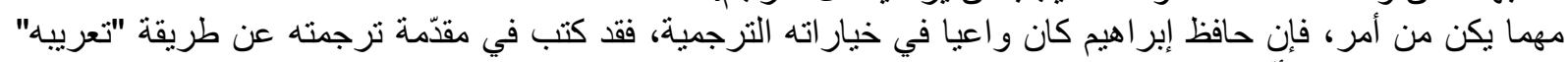

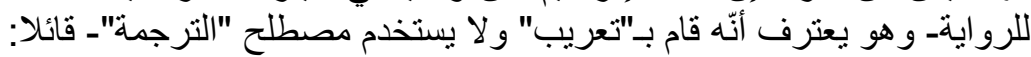

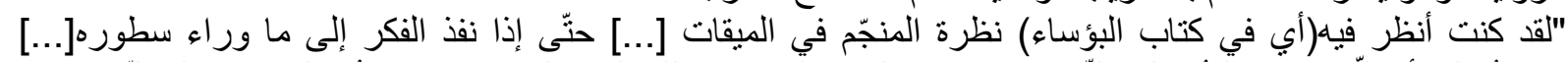

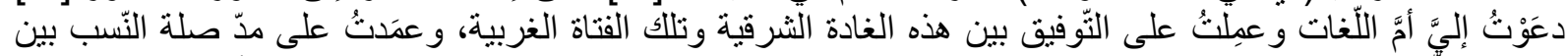

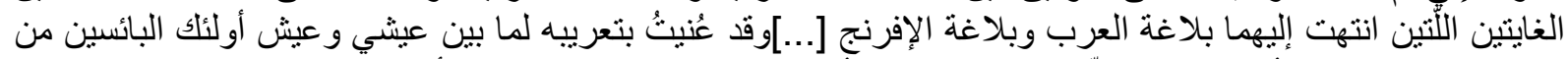

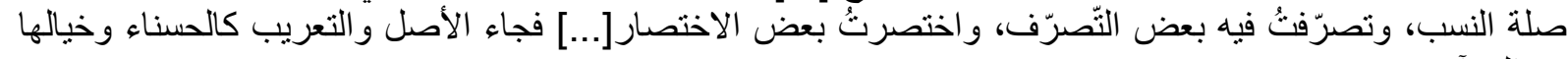

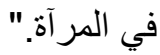


وفي الجانب الأخر، يقول الكاتب الباحث و الإعلامي كمال محمد أن " القارئ العربي، إن لم يكن قد قرأ ترجمة الأديب

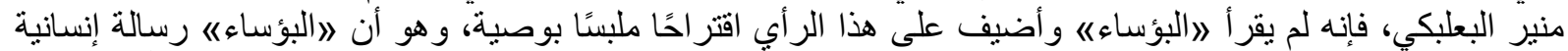

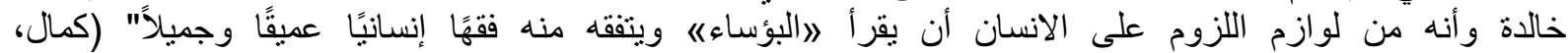

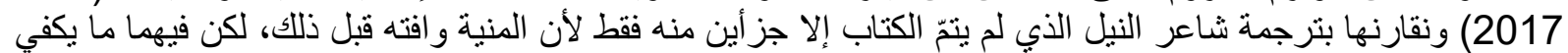

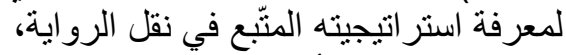

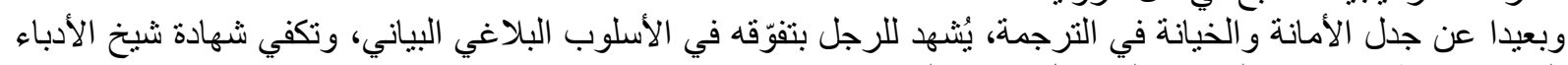

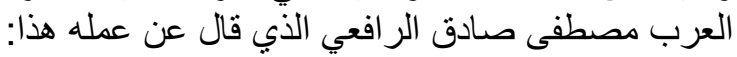

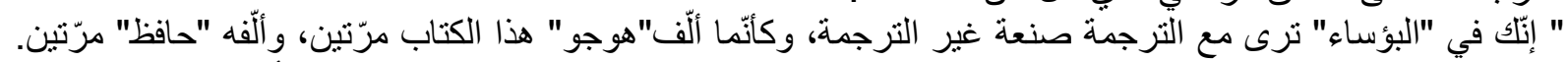

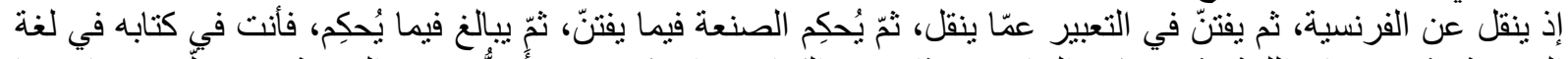

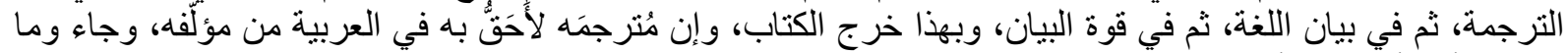

يستطيع أحد أن ينسى أنه لحافظ دون سو اه.

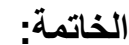

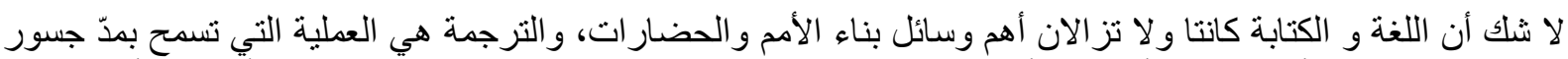

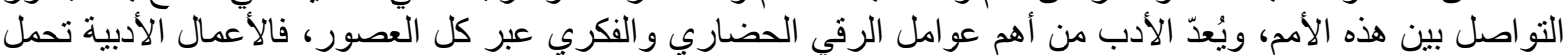

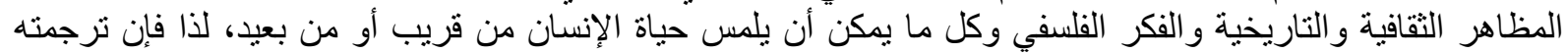

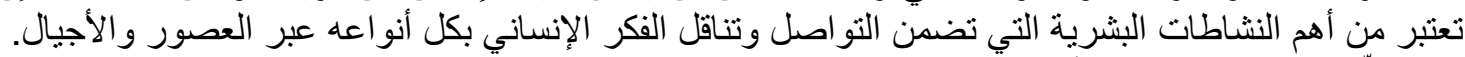

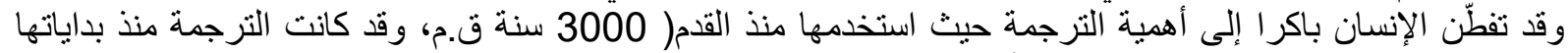

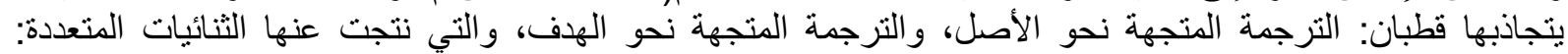

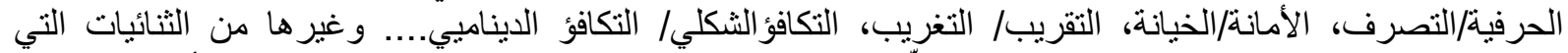

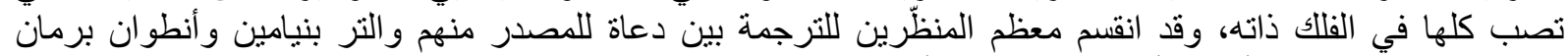

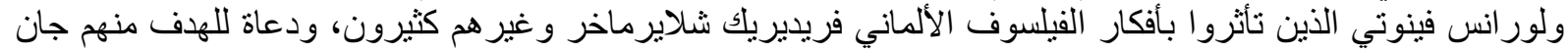

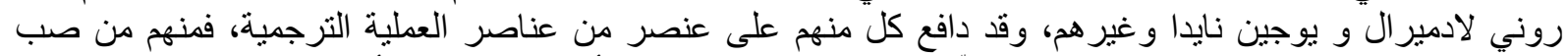

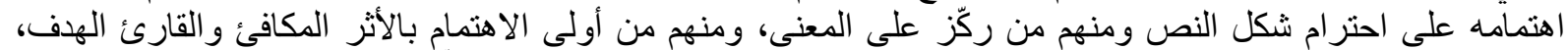

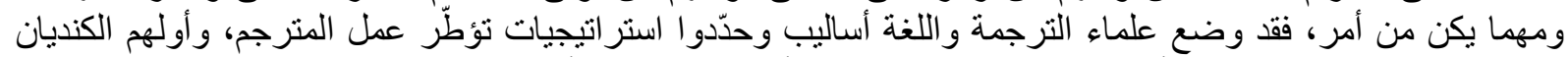

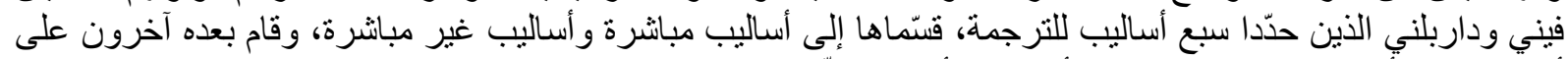

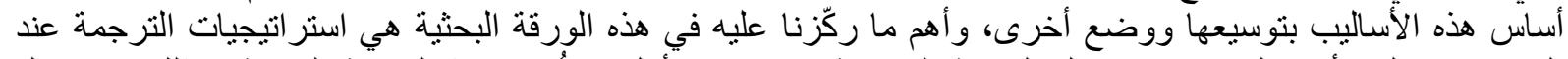

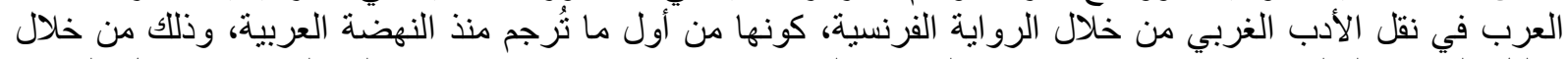

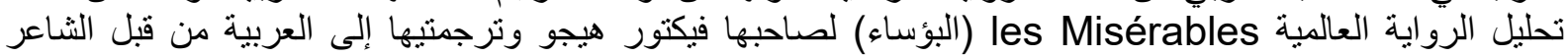

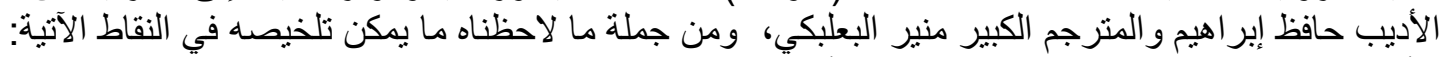

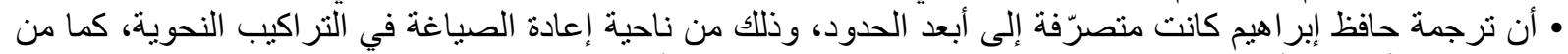

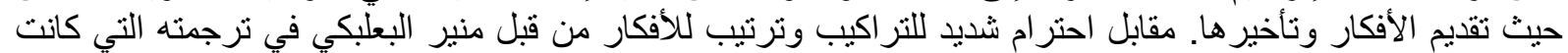
غاية في الحرفية.

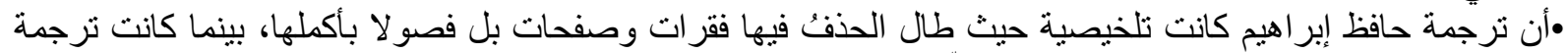

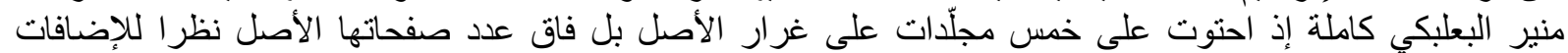

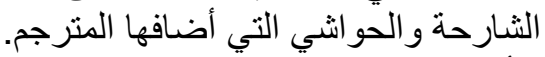

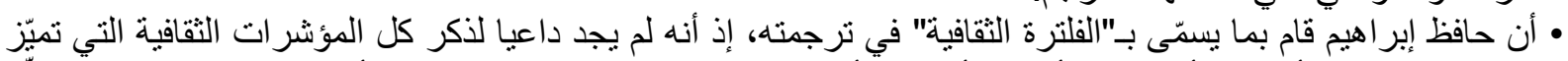

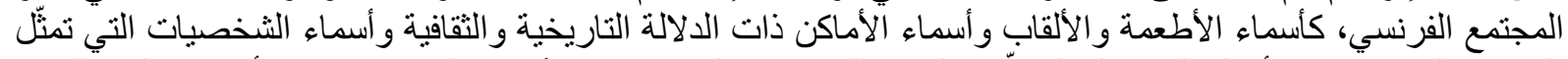

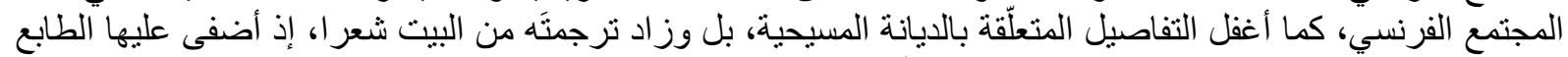

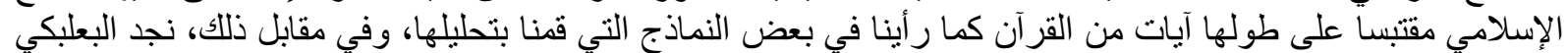

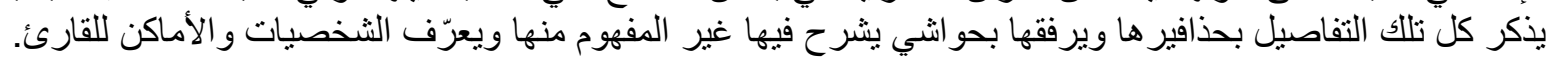

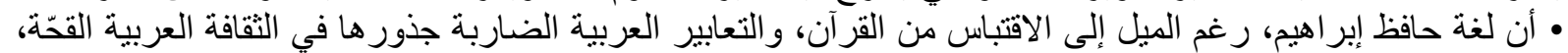

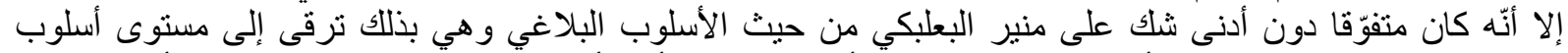

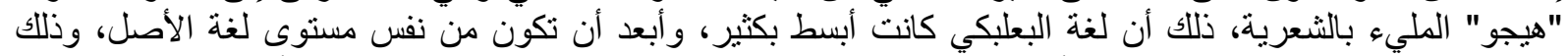

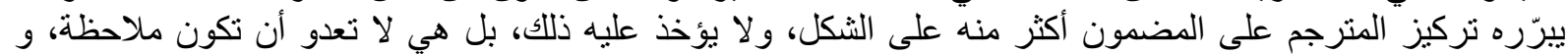

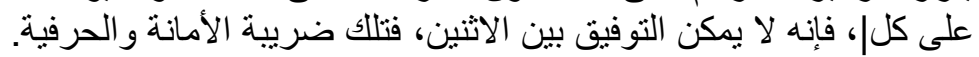

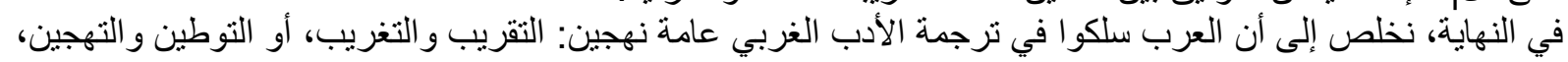

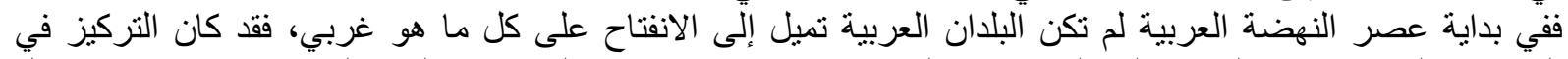

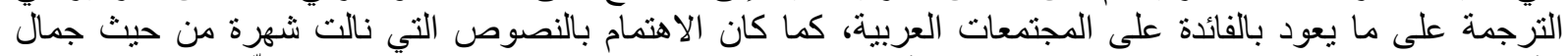

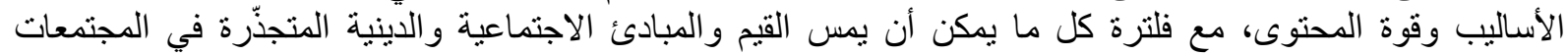




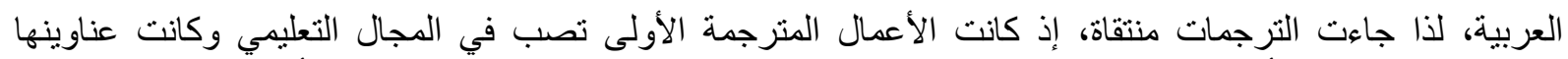

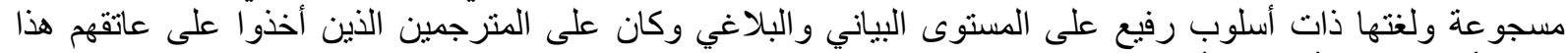

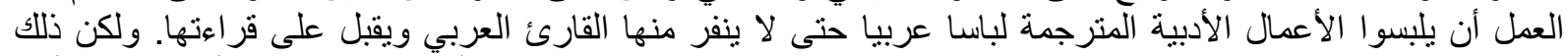

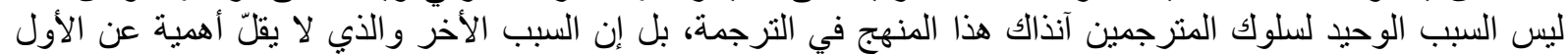

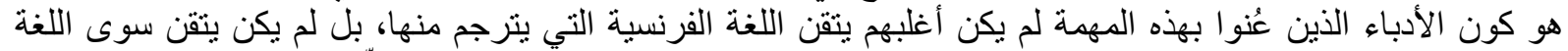

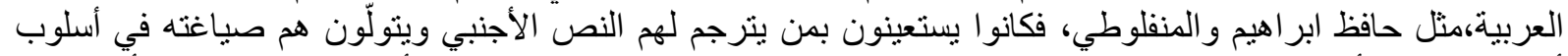

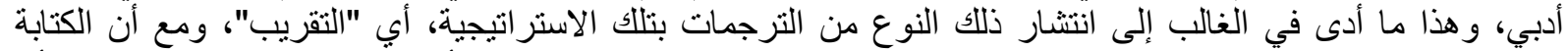

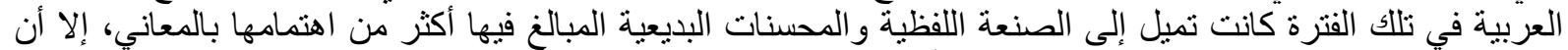

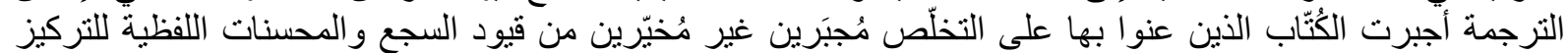

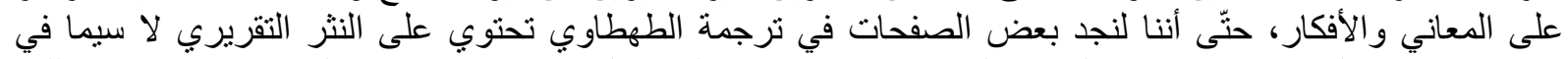

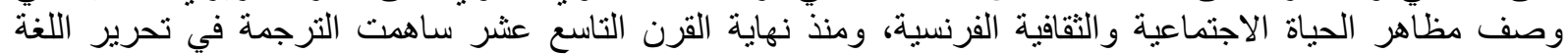

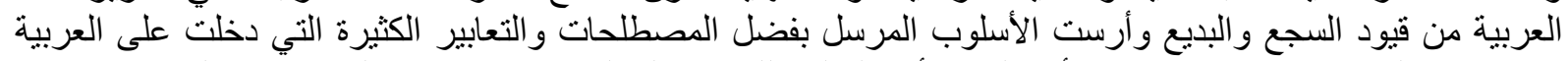

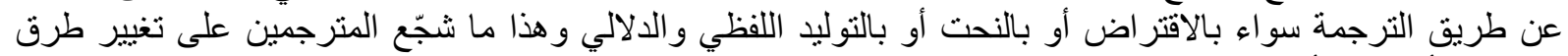

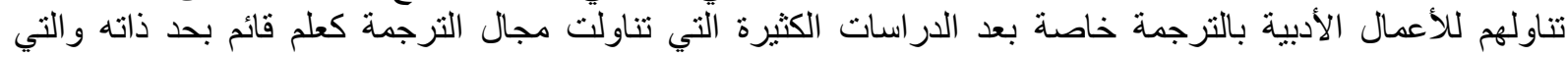

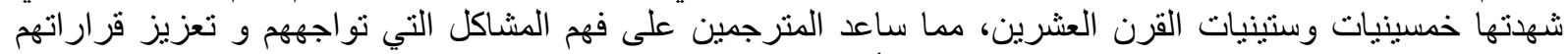

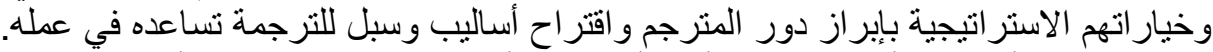

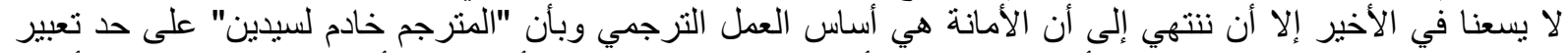

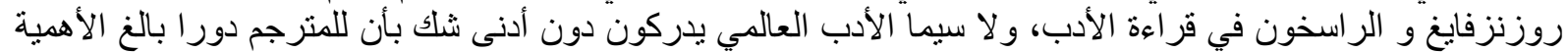

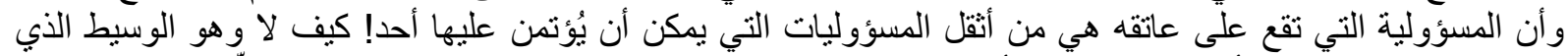

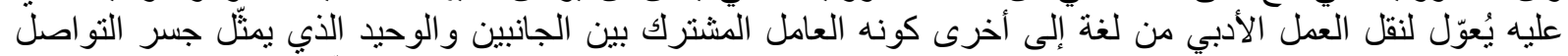

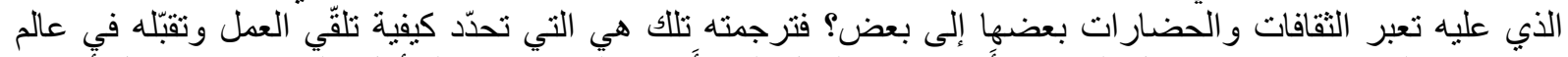

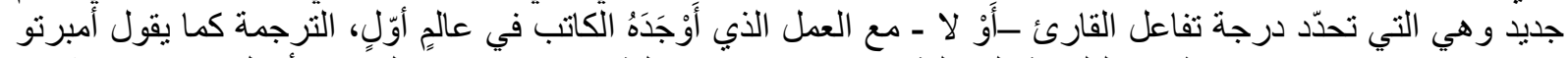

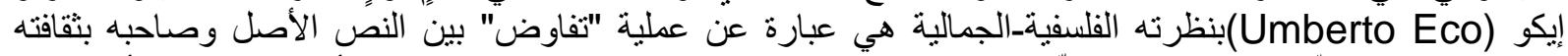

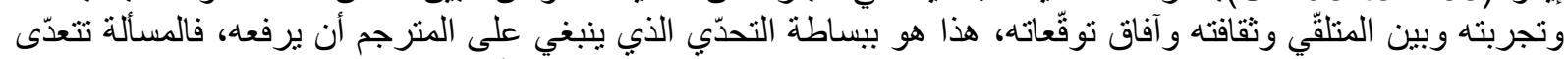

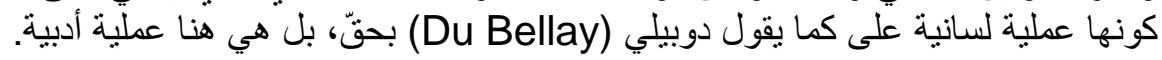

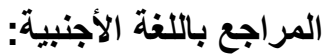

elghrib.blogspot.com/p/blog-page-7479html "Littérature "Dctionnaire Littré https://www.littre.org/definition/litt\%C3\%A9rature

Fortunato Israël .1990) .Traduction littéraire et théorie du sens .Lettres Modernes ، .37

Fortunato Israël .(2006) .Souvent esns varie, le traducteur face à l'instabilité du sens . Lettres Modernes Minard.20,11,

Georges Steiner (1978). Après Babel) .Lucienne Lotringer (المترجمون، Paris ،France: Albin Michel.

Guy Sorman باريخ الاسترداد 05 03, 2016، من Culture-Langage. (بلا تاريخ). www.philo5.com

Jean Louis CALVET .(2017) .La sociolinguistique .Paris: PUF.

Meschonic, H. (2012). Poétique du traduire. Paris: Verdier.

Meschonnic, H. (1972). Langages. Consulté le 06 12, 2019, sur Propositions pour une poétique de la traduction: http://doi.org/10.3406/lgge.1972.2097

Mounin, G. (2016). Les Belles infidèles. Lille: Presses Universitaires du Septentrion.

Biographie de Victor HUGO) .S.D ناريخ الاسترداد 02 02, 2020، من/MAISONS Victor HUGO: http://www.maisonsvictorhugo.paris.fr/fr/victor-hugo/biographie-devictor-hugo

Victor HUGO .(1885) .Les Misérables .Paris: Robert Laffont. 
المعاني. (بلا تاريخ). تاريخ الاسترداد 10 12, 2019، من تعريف ومعنى لغة في معجم المعاني عربي-عربي: www.almaany.com/ar/dict/ar-ar

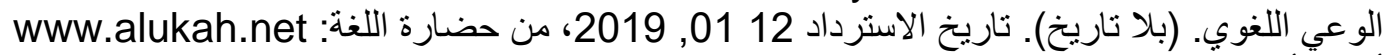
أماني أبو رحمة. (25 01, 2016). حركة اللغاريخ الترجمة في العالم العربي. تاريخ الاسترداد 30 01 012, 2020، من دار

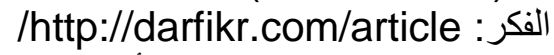

أنطوان برمان. (2010). الترجمة والحرف أو مقام البعد. (عز الدين الخطابي، الكترجمون) بيروت: المنظمة العربية اللترجمة.

انطوان نعمة وآخرون. (2003). المنجد الوسيط. بيروت: دار الششرق.

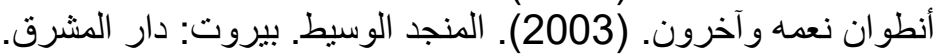
إيمان علي. (18 06, 2010). إلى الجحيم أيها المترجم. تاريخ الاسترداد 23 05 05, 2019، من روز اليوسف: www.masress.com/rosadaily/68905

تعريف ومعنى الأدب في معجم المعاني الجامع. (بلا تاريخ). ناريخ الاسترداد 03 01, 2019، 2019، من المعاني: https://www.almaany.com/ar/dict/ar-ar

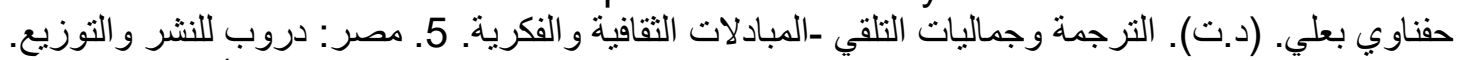

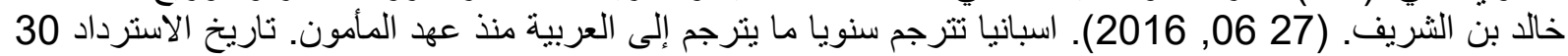

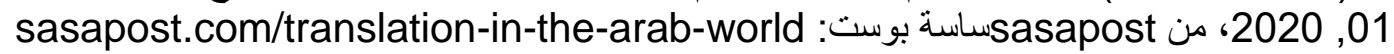

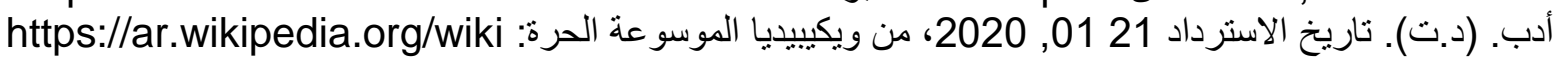

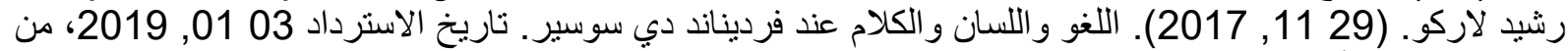

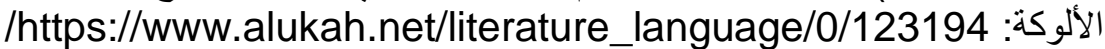

رويدة طه. (27 01, 2017). 2017. أدب دوستيوفسكي...هو امش على الألم والغضب والغربة. تاريخ الاسترداد 24 01,

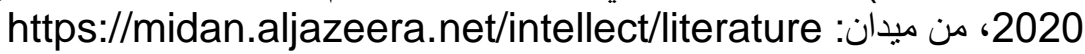

شاهر أحمد نصر. (02 04, 2005) 2005). دور الترجمة في نثر الفكر التنويري في عصر النهضة. تاريخ الاسترداد 01

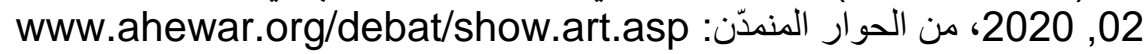
عبد الرحمن ابن خلدون. (2007). الدقدمة. القاهرة: دار الغد الجديد.

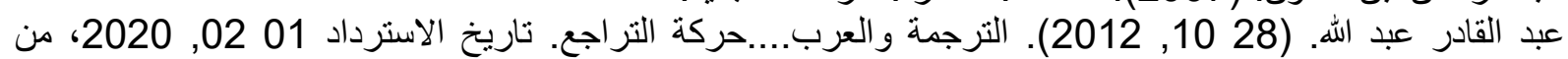

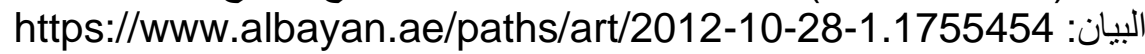

$$
\text { فكتور هيجو. (1955). البؤساء. (منير البعلبكي، المترجمون) بيروت: دار المالايين للنشر. }
$$

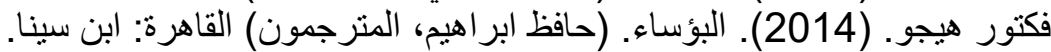

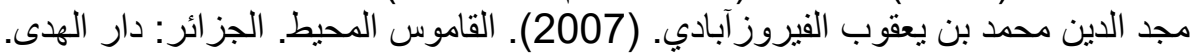

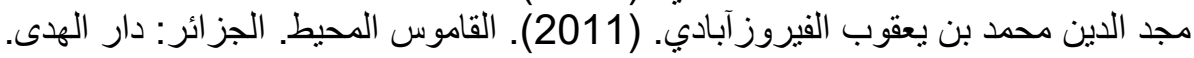
محمد كمال. (12 سبتمبر, 2017). رواية البؤساء وبؤس الترجمات العربية. تاريخ الاسترداد 04 02, 2020، 2020، من https://www.alayam.com/Article/courts-article الأيخام

محمود الأسد. (د,ت). الأدب و علاقتته بالمجتمع. تاريخ الاسترداد 22 01, 2020، من النبأ: org/arabic/literature/943.anabaâ

محمود حواس. (02 02, 2019). الأب والمجتمع. تاريخ الاسترداد 01 02, 2020، من الأيام: https://www.alayam.com/alayam/Variety/777746/News.html

elghrib.blogspot.com/p/blog-page- مدونة الغريب. (بلا تاريخ). تاريخ الاسترداد 20 03, 2016، من 7479html

مصطفى صادق الر افعي. (2010). تاريخ آداب العرب (المجلد ج1). القاهرة: دار ابن الجوزي.

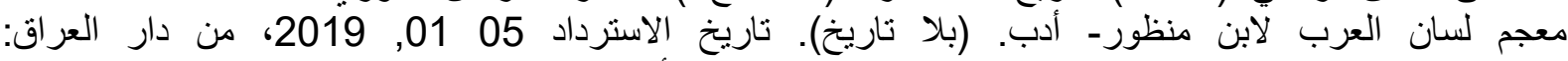
http://wiki.dorar-aliraq.net/lisan-alarab 